OPEN ACCESS

Edited by:

Sigrun Reumann,

University of Hamburg, Germany

Reviewed by:

Ralf Erdmann,

Ruhr University Bochum, Germany

Xuequn Chen,

Wayne State University, United States

Andrew Simmonds,

University of Alberta, Canada

*Correspondence:

Michael Schrader

m.schrader@exeter.ac.uk

tThese authors have contributed

equally to this work

FORCID:

Ruth E. Carmichael orcid.org/0000-0003-2665-2966

Werner J. Kovacs

orcid.org/0000-0002-4440-4344

Michael Schrader

orcid.org/0000-0003-2146-0535

Specialty section:

This article was submitted to

Membrane Traffic,

a section of the journal

Frontiers in Cell and Developmental

Biology

Received: 29 June 2020

Accepted: 01 October 2020

Published: 23 October 2020

Citation:

Azadi AS, Carmichael RE,

Kovacs WJ, Koster J, Kors S,

Waterham HR and Schrader M (2020)

A Functional SMAD2/3 Binding Site

in the PEX11 $\beta$ Promoter Identifies

a Role for TGF $\beta$ in Peroxisome

Proliferation in Humans.

Front. Cell Dev. Biol. 8:577637.

doi: 10.3389/fcell.2020.577637

\section{A Functional SMAD2/3 Binding Site in the PEX11 $\beta$ Promoter Identifies a Role for TGF $\beta$ in Peroxisome Proliferation in Humans}

\author{
Afsoon S. Azadi't, Ruth E. Carmichael'1t, Werner J. Kovacs²f, Janet Koster ${ }^{3}$, \\ Suzan Kors ${ }^{1}$, Hans R. Waterham ${ }^{3}$ and Michael Schrader ${ }^{1 * \neq}$ \\ ${ }^{1}$ Biosciences, College of Life and Environmental Sciences, University of Exeter, Exeter, United Kingdom, ${ }^{2}$ Institute \\ of Molecular Health Sciences, Swiss Federal Institute of Technology in Zürich (ETH Zürich), Zurich, Switzerland, ${ }^{3}$ Laboratory \\ Genetic Metabolic Diseases, Amsterdam University Medical Centres, University of Amsterdam, Amsterdam, Netherlands
}

In mammals, peroxisomes perform crucial functions in cellular metabolism, signaling and viral defense which are essential to the viability of the organism. Molecular cues triggered by changes in the cellular environment induce a dynamic response in peroxisomes, which manifests itself as a change in peroxisome number, altered enzyme levels and adaptations to the peroxisomal morphology. How the regulation of this process is integrated into the cell's response to different stimuli, including the signaling pathways and factors involved, remains unclear. Here, a cell-based peroxisome proliferation assay has been applied to investigate the ability of different stimuli to induce peroxisome proliferation. We determined that serum stimulation, long-chain fatty acid supplementation and TGF $\beta$ application all increase peroxisome elongation, a prerequisite for proliferation. Time-resolved mRNA expression during the peroxisome proliferation cycle revealed a number of peroxins whose expression correlated with peroxisome elongation, including the $\beta$ isoform of PEX11, but not the $\alpha$ or $\gamma$ isoforms. An initial map of putative regulatory motif sites in the respective promoters showed a difference between binding sites in PEX $11 \alpha$ and PEX $11 \beta$, suggesting that these genes may be regulated by distinct pathways. A functional SMAD2/3 binding site in PEX11 $\beta$ points to the involvement of the TGF $\beta$ signaling pathway in expression of this gene and thus peroxisome proliferation/dynamics in humans.

Keywords: peroxisomes, organelle dynamics, transcriptional regulation, peroxin, PEX11, transforming growth factor beta

\footnotetext{
Abbreviations: AA, arachidonic acid; ABCD, ATP-binding cassette sub-family D; ACAA1, acetyl-CoA acyltransferase 1; ACOX1, acyl-CoA oxidase 1; AGPS, alkylglycerone phosphate synthase; CRAT, carnitine O-acetyltransferase; CROT, carnitine O-octanoyltransferase; DHA, docosahexaenoic acid; DRP1, dynamin-related protein 1; EHHADH, enoyl-CoA hydratase and 3-hydroxyacyl-CoA dehydrogenase; FAR1, fatty acyl-CoA reductase 1; FBS, fetal bovine serum; FIS1, mitochondrial fission 1 protein; GNPAT, glyceronephosphate $O$-acyltransferase; LA, linoleic acid; MFF, mitochondrial fission factor; mTOR, mammalian target of rapamycin; OA, oleic acid; PA, palmitic acid; PEX, peroxisome biogenesis factor (peroxin); PGC1, PPAR gamma coactivator 1; PMP, peroxisomal membrane protein; PPAR, peroxisome proliferator activated receptor; PPRE, peroxisome proliferator response element; PUFA, polyunsaturated fatty acid; SMAD, small worm phenotype/mothers against decapentaplegic homolog; TGF $\beta$, transforming growth factor $\beta$; VLCFA, very-long-chain fatty acid.
} 


\section{INTRODUCTION}

Peroxisomes represent crucial subcellular compartments that are essential for human life and health. They perform key roles in cellular lipid metabolism, for example the breakdown and detoxification of fatty acids by $\alpha$ - and $\beta$-oxidation, and the synthesis of ether-phospholipids (e.g., plasmalogens, which are enriched in myelin sheaths), bile acids and polyunsaturated fatty acids (e.g., DHA) (Wanders, 2013a). Peroxisomes also contribute to hydrogen peroxide metabolism, cellular redox balance and redox signaling (Fransen and Lismont, 2018). Defects in peroxisome metabolic functions or biogenesis result in severe disorders with developmental and neurological defects (Wanders, 2013b; Braverman et al., 2016).

Peroxisomes are remarkably dynamic organelles, which respond to stimulation by adapting their morphology, abundance, and metabolic functions according to cellular needs. New peroxisomes can form from pre-existing peroxisomes by membrane growth and division, which results in their multiplication/proliferation (Schrader et al., 2016). Growth and division in mammalian cells follows a well-defined multi-step process of morphological alterations including elongation/remodeling of the peroxisomal membrane, constriction and recruitment of division factors (e.g., the adaptor proteins MFF, FIS1), and final membrane scission (by the dynamin-related GTPase DRP1) (Schrader et al., 2016). The membrane shaping peroxisomal membrane protein PEX11 $\beta$ contributes to multiple steps of peroxisomal growth and division including membrane deformation and elongation (Delille et al., 2010; Opaliński et al., 2011), recruitment of MFF and FIS1 to constriction sites (Koch et al., 2005; Koch and Brocard, 2012; Itoyama et al., 2013), and activation of DRP1 for membrane fission (Williams et al., 2015). Besides PEX11 $\beta$, humans express two additional PEX11 isoforms, PEX11 $\alpha$ and PEX11 $\gamma$, but their exact functions are unclear and may differ, given that both isoforms cannot or only partially complement loss of PEX11 $\beta$ (Ebberink et al., 2012). So far, only patients with a defect in the $\beta$ isoform of PEX11 have been identified, who present with enlarged peroxisomes, congenital cataracts, progressive hearing loss, short stature and neurological abnormalities (Ebberink et al., 2012; Taylor et al., 2017; Tian et al., 2019).

Although our understanding of the mechanisms by which peroxisomes proliferate is increasing, we have limited knowledge of how peroxisome biogenesis and division/multiplication is regulated by stimuli. In plants, it has been suggested that peroxisome proliferation can be stimulated by light, due to an increase in $P E X 11 b$ transcription regulated by the transcription factors HYH and FHA3 (Desai and Hu, 2008; Desai et al., 2017). However, relatively little is known about how extracellular signals feed into peroxisome biogenesis in mammals and especially in humans. The best characterized regulatory pathway in mammals is the peroxisome proliferator-activated receptor (PPAR)-dependent pathway (Kliewer et al., 1992; Schrader et al., 2012b). PPARs are a family of transcription factors which modulate transcription of target genes in response to a variety of structurally diverse ligands, including xenobiotic chemicals called peroxisome proliferators, and both natural and synthetic fatty acids (Rakhshandehroo et al., 2010). PPAR $\alpha$ is expressed predominantly in the liver, heart and brown adipose tissue, and is a major activator of fatty acid oxidation pathways (la Cour Poulsen et al., 2012). PPAR $\gamma$ is most highly expressed in white and brown adipose tissue, and functions as a master regulator of adipogenesis as well as a potent modulator of wholebody lipid metabolism and insulin sensitivity (Tontonoz and Spiegelman, 2008; Dubois et al., 2017; Kersten and Stienstra, 2017). PPAR $\beta / \delta$ is the most poorly characterized isoform, but is ubiquitously expressed and is thought to be important in lipid and cholesterol metabolism (Grygiel-Górniak, 2014). Upon ligand binding, PPARs hetero-dimerise with their binding partner, the 9-cis-retinoic acid receptor, $\mathrm{RXR} \alpha$, and bind to specific cis-acting DNA response elements known as PPRE, to initiate gene transcription. ChIP-seq analysis in human hepatoblastoma HepG2 cells revealed PPAR $\alpha$-occupied PPREs in genes encoding for peroxisomal enzymes such as ACOX1 (van der Meer et al., 2010), suggesting that their expression is regulated by PPAR $\alpha$.

PPAR $\alpha$ agonists can significantly increase peroxisome number and the levels of fatty acid $\beta$-oxidation enzymes (Lazarow and De Duve, 1976; Schrader et al., 2016), but whilst rodents usually respond with a strong peroxisome proliferation phenotype, the effect in humans is very mild (Lawrence et al., 2001; Islinger et al., 2010). Although there is evidence for a functional PPRE in the promoter region of the PEX11 $\alpha$ gene in both mouse (Shimizu et al., 2004) and human (Rakhshandehroo et al., 2010), there is little information so far on transcriptional regulation of other PEX genes in mammals, and especially humans. For example, there is currently no evidence for up-regulation of human PEX11 $\beta$, as a key factor in peroxisome proliferation, following stimulation with PPAR $\alpha$ agonists. In line with this, there is growing evidence that PPAR-independent pathways exist which can be activated by extracellular signals such as ROS and growth factors (Schrader and Fahimi, 2006; Bagattin et al., 2010; Fransen et al., 2012). Although the involvement of a variety of regulatory pathways in controlling transcription of peroxisome proliferation related genes under different conditions has been suggested, it is currently unclear how up-regulation of peroxisomal genes is linked to up-regulation of peroxisome proliferation.

Several studies have implicated the growth factor TGF $\beta$ in the regulation of peroxisomes, and while it has been suggested to both increase (Schrader et al., 1998a) and decrease (Oruqaj et al., 2015) peroxisome biogenesis under different conditions, the direct targets involved in this process are unclear. The TGF $\beta$ family consists of multifunctional proteins that regulate a diverse range of processes during development and tissue homeostasis, such as cell proliferation, apoptosis, autophagy, inflammation, angiogenesis, and epithelialto-mesenchymal transition (Kitisin et al., 2007; Nagaraj and Datta, 2010; Horbelt et al., 2012; Massagué, 2012). There are three known isoforms of TGF $\beta$ (TGF $\beta 1$, TGF $\beta 2$, and TGF 33 ) expressed in mammalian tissues; they contain highly conserved regions but are different in several amino acid sequences. All of these isoforms function through the same receptor signaling pathways (Horbelt et al., 2012). TGF $\beta$ isoforms bind to receptors at the cell surface, and recruit two type I 
receptors and two type II receptors forming a tetrameric complex (Massagué, 2012). Activated TGF $\beta$ superfamily receptors induce a phosphorylation cascade, from receptor phosphorylation to subsequent phosphorylation and activation of downstream signal transducer R-SMAD transcription factors (receptoractivated SMADs, including SMAD2/3) (Hill, 2016; Miyazawa and Miyazono, 2017). Phosphorylated R-SMADs form a hetero-oligomeric (often trimeric) complex with SMAD4. This R-SMAD/SMAD4 complex is imported into the nucleus where it regulates the expression of target genes by direct binding to specific motifs in the target gene promoter and/or through interaction with transcriptional cofactors in a celltype-specific manner (Hariharan and Pillai, 2008; Kamato et al., 2013). SMAD target genes include the transcription factors PGC- $1 \alpha$ and PPAR $\gamma$, classically thought to regulate peroxisome proliferation, with elevated TGF $\beta$ signaling leading to systemic insulin resistance and hepatic steatosis through decreased expression of these target proteins (Yadav et al., 2011; Sohn et al., 2012). Additionally, PPAR $\alpha$ may act upstream of TGF $\beta$-dependent gene transcription, with PPAR $\alpha$ ligands reported to decrease TGF $\beta$-induced integrin expression by inhibiting SMAD4 complex formation (Kintscher et al., 2002), suggesting a complex interplay between TGF $\beta$ signaling and PPAR function.

Since deficiencies in peroxisome proliferation have been associated with a variety of disease states, including liver diseases and neurological dysfunction, as well as cellular aging (Cimini et al., 2009; Titorenko and Terlecky, 2011; Schrader et al., 2014; Passmore et al., 2020), a clearer understanding of the mechanisms and signaling pathways that control peroxisome plasticity could allow for modulation of peroxisome abundance to improve cellular function in health and disease. In this study, we aimed to identify novel signaling pathways and associated factors involved in peroxisome dynamics in humans, using a cellbased assay to investigate different stimuli and their ability to induce peroxisome proliferation. Examination of mRNA levels during peroxisome proliferation suggested differential regulation of peroxisomal genes correlating with their cellular function. Specifically, we identified differential regulation and functions of the PEX11 isoforms PEX11 $\alpha$ and PEX11 $\beta$ in peroxisome dynamics. A functional SMAD2/3 binding site in the promoter of PEX11 $\beta$ suggests a novel link between the canonical TGF $\beta$ signaling pathway and the induction of peroxisome proliferation, potentially via PEX11 $\beta$ expression, providing new insights into the regulation of peroxisome dynamics in humans.

\section{MATERIALS AND METHODS}

\section{Plasmids and Antibodies}

For cloning of PEX11 $\beta$ promoter regions, the candidate promoter region (1,302 bp for the wild type and 1,296 bp for the mutant lacking the SMAD2/3 binding site) of human PEX11 $\beta$ was synthesized (Eurofins Genomics) and then cloned into the pGL3-basic vector upstream of the firefly luciferase coding sequence (\#E1751, Promega). The pGL3-basic vector without a promoter was used as a negative control. pRL-TK vector (\#E2231,
Promega) was used as internal control vector to normalize luciferase activities. See Supplementary Table 1 for details of plasmids used in this study, Supplementary Table 2 for plasmids generated in this study and Supplementary Table 3 for details of qPCR primers used. All constructs produced were confirmed by sequencing (Eurofins Genomics). Details of all antibodies used in this study can be found in Supplementary Table 4.

\section{Cell Culture and Cell-Based Peroxisome Proliferation Assay}

For routine culture, HepG2 cells (human hepatoblastoma cells, HB8065; ATCC) were maintained in Minimal Essential Medium (MEM; Life Technologies) supplemented with 10\% FBS, $(100 \mathrm{U} / \mathrm{ml}$ penicillin and $100 \mu \mathrm{g} / \mathrm{ml}$ streptomycin $)$ at $37^{\circ} \mathrm{C}$ in a $5 \% \mathrm{CO}_{2}$-humidified incubator. COS-7 (African green monkey kidney cells, CRL-1651; ATCC), PEX11 $\beta$-deficient skin fibroblasts (Ebberink et al., 2012) and PEX11 KO HeLa cells were cultured in Dulbecco's Modified Eagle's Medium (DMEM; Life Technologies) supplemented as above. COS-7 cells were transfected using diethylaminoethyl (DEAE)-dextran (SigmaAldrich) as described (Bonekamp et al., 2010). For stimulation experiments, HepG2 cells were cultured in serum-free MEM with $\mathrm{N} 1$ supplement [Sigma: $0.5 \mathrm{mg} / \mathrm{ml}$ recombinant human insulin, $0.5 \mathrm{mg} / \mathrm{ml}$ human transferrin (partially iron-saturated), $0.5 \mu \mathrm{g} / \mathrm{ml}$ sodium selenite, $1.6 \mathrm{mg} / \mathrm{ml}$ putrescine, and $0.73 \mu \mathrm{g} / \mathrm{ml}$ progesterone] containing $0.25 \%$ BSA. For morphological analysis of peroxisomes, $70,000 / \mathrm{cm}^{2}$ HepG2 cells were seeded on collagen (Serva)-coated glass coverslips. Compounds/inhibitors were added $6 \mathrm{~h}$ after seeding and cells were processed for immunofluorescence at different time points after incubation (as indicated in Figures). Fatty acid stocks (Sigma-Aldrich) were dissolved in ethanol. WY-14643 (\#C7081), Troglitazone (\#T2573), GW9962 (\#M6191), Rapamycin (\#R0395), LY2109761 (\#SML2051), and SB431542 (\#616461) were obtained from Sigma-Aldrich. Recombinant human TGF $\beta$ was obtained from R\&D Systems (\#240-B). Stimulation with $10 \%$ FBS served as a positive control for peroxisome elongation/proliferation.

\section{Generation of PEX11-Deficient HeLa Cells by CRISPR-Cas9}

For each PEX11 gene, two different sgRNA guide sequences targeting an exon of PEX11 $\alpha$, PEX11 $\beta$, or PEX11 $\gamma$ were selected using the CRISPR Design Tool ${ }^{1}$ (Ran et al., 2013) (Supplementary Table 5). Complementary guide oligos were annealed and subsequently cloned into the pX458 [-pSpCas9(BB)-2A-GFP] plasmid (Addgene). Cells were transfected in six-well plates with $2 \mu \mathrm{g}$ plasmid containing

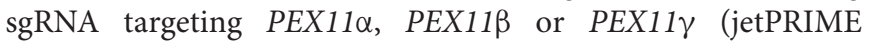
DNA Transfection). Single GFP-positive cells were sorted by fluorescence-activated cell sorting into 96-well plates (SH800 Cell Sorter, Sony Biotechnology) as described (Ran et al., 2013). After $\sim 4$ weeks, DNA was isolated from multiple expanded single colonies, and the targeted exon of the PEX11 genes were PCR amplified using Phire Hot Start II DNA Polymerase (Thermo

\footnotetext{
${ }^{1}$ http://crispr.mit.edu/
} 
Fisher Scientific) and subsequently Sanger sequenced to confirm clonal populations with heterozygous mutations in $P E X 11 \alpha$,

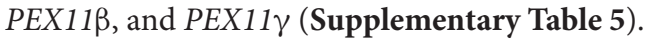

\section{Transfection and Dual Luciferase Reporter Assay}

$2 \times 10^{5}$ HepG2 cells/well were seeded the day before transfection in 6-well plates in $1.5 \mathrm{ml}$ complete growth MEM. $1 \mu \mathrm{g}$ of the desired pGL3 vector DNA and 40 ng pRL-TK vector DNA (ratio 25:1) was transfected per well using Lipofectamine 3000 (Invitrogen) according to instructions.

$48 \mathrm{~h}$ after transfection, cells were seeded in MEM/N1 media in 96 cell plates. $6 \mathrm{~h}$ after seeding, cells were treated with TGF $\beta$, FBS or left untreated and were incubated for $24 \mathrm{~h}$ prior to performing the Dual-Luciferase Reporter assay (Promega, \#E1910) with a MicroLumat Plus LB 96V luminometer (Berthold Technologies), according to manufacturer's instructions. Luminescence was measured for $10 \mathrm{~s}$, and each reaction was measured three times. For analysis, Firefly luciferase activities were normalized to Renilla luminescence in each well.

\section{RNA Isolation and Quantitative PCR}

Total RNA was prepared from HepG2 cells with the NucleoSpin RNA Kit (\#740955.50; Macherey-Nagel) and DNA was removed by on-column digestion with rDNase. cDNA was synthesized from $2 \mu \mathrm{g}$ RNA with random hexamer primers using the HighCapacity RNA-to-cDNA Kit (\#4368813; Applied Biosystems) and diluted 10 -fold in sterile $\mathrm{H}_{2} 0$. The real-time qPCR reaction was performed on a Roche LightCycler LC480 instrument in duplicates using $10 \mathrm{ng}$ CDNA, $7.5 \mathrm{pmol}$ forward and reverse primers, and the $2 \times$ KAPA SYBR FAST qPCR Mastermix (\#KK4601; KAPA Biosystems). Thermal cycling was carried out with a 5 min denaturation step at $95^{\circ} \mathrm{C}$, followed by 45 three-step cycles: $10 \mathrm{~s}$ at $95^{\circ} \mathrm{C}, 10 \mathrm{~s}$ at $60^{\circ} \mathrm{C}$, and $10 \mathrm{~s}$ at $72^{\circ} \mathrm{C}$. Melt curve analysis was carried out to confirm the specific amplification of a target gene and absence of primer dimers. Relative mRNA amount was calculated using the comparative threshold cycle method. 18S rRNA was used as the invariant control.

\section{Immunofluorescence and Microscopy}

Cells were processed for immunofluorescence 24-48 h after transfection. Cells grown on collagen-coated glass coverslips were fixed for $20 \mathrm{~min}$ with $4 \%$ (w/v) para-formaldehyde in PBS (pH 7.4), permeabilized with $0.2 \%$ (w/v) Triton X-100 for 10 min and blocked with $1 \%$ BSA for 10 min. Blocked cells were sequentially incubated with primary and secondary antibodies for $1 \mathrm{~h}$ in a humid chamber. Coverslips were washed with $\mathrm{dd}_{2} \mathrm{O}$ to remove PBS and mounted with Mowiol medium (containing $25 \%$ n-propyl-gallate as anti-fading reagent) on glass slides. All immunofluorescence steps were performed at room temperature and cells were washed three times with PBS, pH 7.4 between each individual step. Cell imaging was performed using an Olympus IX81 microscope equipped with an UPlanSApo $100 \times / 1.40$ oil objective (Olympus). Digital images were taken with a CoolSNAP HQ2 CCD camera. Representative images only were adjusted for contrast and brightness using the Olympus Soft Imaging Viewer software (Olympus) and MetaMorph 7 (Molecular Devices).

\section{Promoter Analysis}

For each PEX11 isoform gene, regions 10kb upstream of the start codon were scanned base-pair by base-pair for regulatory elements using the GimmeMotif programme (van Heeringen and Veenstra, 2010). To obtain transcription factor binding site motifs to search for, position weight matrices representing the DNA binding preferences of 700 transcription factors were imported from the JASPAR CORE database ${ }^{2}$. Bona fide binding sites in the regulatory region for each chosen gene were defined as having a higher than $89 \%$ potential match to a JASPAR motif. Binding efficiency to SMAD2/3 motifs was calculated relative to the JASPAR position weight matrix consensus sequence (ID MA0513.1). In order to eliminate non-active motif binding sites based on chromosome structure, the presence of H3K4me3, H3K36me3, H3K27ac histone marks and absence of H3K27m3 near the potential motif was checked with the USCS Genome Browser as indicators of transcriptionally active sites in HepG2 cells. The ENCODE database of transcription factor binding tracks was used to exclude transcriptionally silent sites in each gene (those with a score of $<500$ out of 1000 for ChIP-seq evidence of transcription factor binding).

\section{Quantification and Statistical Analysis of Data}

For quantitative analysis of peroxisome morphology, 100-200 cells per coverslip were examined and categorized possessing elongated/tubular ( $>2 \mu \mathrm{m}$ in length) or spherical peroxisomes (0.3-2 $\mu \mathrm{m}$; including rod-shaped peroxisomes) (Schrader et al., 1996). For quantification of peroxisome number, images were acquired in the focal plane of the nucleus, and peroxisome number per cell was determined using an in-house ImageJ macro (Schneider et al., 2012; Passmore et al., 2020) based on the 'Analyze Particles' function. Usually, three coverslips per preparation were analyzed, and three independent experiments were performed. Statistical analyses were performed using GraphPad Prism 5 software. Data are presented as means \pm SD. Two-tailed unpaired $t$-tests (for experiments with two groups) or one-way ANOVAs with appropriate post hoc tests (for experiments with three or more groups) were used to determine statistical differences against control values (see Figure Legends for details). ${ }^{*} p<0.05,{ }^{* *} p<0.01,{ }^{* * *} p<0.001$, ns, nonsignificant.

\section{RESULTS}

\section{Validation of a Cell-Based Peroxisome Proliferation Assay}

Expansion of the peroxisomal membrane is the first in a sequence of morphological changes that occur during peroxisomal growth and division in mammalian cells (Schrader et al., 2016). In human

\footnotetext{
${ }^{2}$ http://jaspar.genereg.net/
} 
hepatoblastoma HepG2 cells, elongated or tubular peroxisomes increase in number for approximately $24 \mathrm{~h}$ after seeding; the number of tubular peroxisomes decreases after this time point as fission occurs and most of the cells show spherical peroxisomal forms (Schrader et al., 1996). This membrane growth and subsequent fission contributes to the multiplication/proliferation of peroxisomes under conditions of cellular growth. In order to characterize and measure the progression of peroxisome proliferation in HepG2 cells, we have established a cellbased proliferation assay to measure synchronous peroxisome dynamics (Figure 1). Alterations in peroxisome morphology under different culture conditions were quantified over time by immunofluorescence microscopy, staining for the peroxisomal membrane protein PEX14 (Nguyen et al., 2006; Grant et al., 2013). Under standard culture conditions (MEM with 10\% FBS [MEM/FBS]), the number of tubular peroxisomes increased in a time-dependent manner in HepG2 cells seeded at a defined density, as previously reported (Schrader et al., 1996). In cells cultured in defined serum-free media (MEM with N1 supplement [MEM/N1]), however, the majority of peroxisomes remained spherical after $24 \mathrm{~h}$ of culture (Figures 1A,B), creating a 'basal' state from which peroxisome tubulation could be induced and measured. By synchronizing peroxisomes in a spherical form in this way, a change in peroxisome morphology could be monitored to determine modulators of peroxisome proliferation.

To validate that our assay system could be used to detect and follow changes in peroxisome morphology in response to environmental stimuli, HepG2 cells were incubated for $6 \mathrm{~h}$ in MEM/N1, where cells display spherical and rodshaped peroxisome morphologies, then exposed to $10 \%$ FBS for $24 \mathrm{~h}$ ('serum stimulation'). Peroxisome morphology was again assessed by PEX14 immunofluorescence. Serum stimulation increased the proportion of cells with tubular peroxisomes to more than $80 \%$ (Figure 1B), whereas peroxisomes remained predominantly spherical in cells kept in serum-free medium. Furthermore, after $48 \mathrm{~h}$, the number of peroxisomes per cell was $60 \%$ higher in serum-stimulated cells compared to those cultured in MEM/N1 (Figure 1C). This confirms that elongated peroxisomes, which peak in number after $24 \mathrm{~h}$, divide by fission and contribute to peroxisome proliferation. These observations indicate that peroxisomal growth and division is reduced under serum-free culture conditions, and therefore that the peroxisomal compartment is responsive to serum stimulation.

To test if cellular growth in MEM/N1 is comparable to standard growth conditions, we determined and compared cellular growth over time. Cells cultured in MEM/N1 display slightly lower growth rates when compared to cells cultured in MEM/FBS (Supplementary Figure 1). However, the cells are actively proliferating and an exponential increase in cell density arises. It should, however, be noted that the cells appear smaller and are not as extensively spread as HepG2 cells grown under standard conditions.

With this cell-based assay, we have established an inducible system to dissect the distinct phases of peroxisome proliferation in a synchronous manner, and test different stimuli and their effect on peroxisome dynamics and proliferation in a quantitative fashion. To verify the assay, we first applied arachidonic acid (AA) $[\mathrm{C} 20: 4(\omega-6)]$ as a positive control. This PUFA serves as a precursor for the synthesis of a number of biologically active lipid mediators and has been reported to induce peroxisome elongation/proliferation in a previous study (Schrader et al., 1998a). Indeed, our results show that $50 \mu \mathrm{M}$ AA causes a prominent increase in the percentage of cells with tubular peroxisomes ( $\sim 3.5$-fold increase compared to the control) (Figure 4A), a similar magnitude of effect as when serum is added to the MEM/N1 medium. The addition of the PUFA linoleic acid (LA) [C18:2 ( $\omega-6)]$ promoted peroxisome elongation, but less than AA or serum stimulation $(\sim 2.6$-fold increase compared

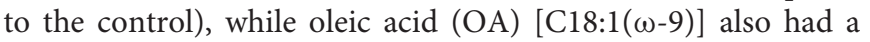
small but significant stimulatory effect on peroxisome elongation ( $\sim 1.4$-fold increase compared to the control). However, the saturated fatty acid palmitic acid (PA) (C16:0) was not able to induce peroxisome membrane expansion at the concentrations applied (Figure 4A), even though, as observed for AA, LA, and $\mathrm{OA}$, the number and size of lipid droplets was increased in the cells (not shown), indicating that all the fatty acids are efficiently taken up and stored by the cells. Together, this suggests a correlation between fatty acid chain length and/or degree of saturation and their ability to induce peroxisome elongation. Shorter-chain fatty acids are preferential substrates for mitochondrial $\beta$-oxidation, while the longer-chain fatty acids, which induce peroxisome elongation, can be $\beta$-oxidized in peroxisomes and/or are involved in the synthesis of cellular lipid mediators.

PUFAs such as AA and LA can act as PPAR ligands (Varga et al., 2011), so we next tested the ability of pharmacological PPAR ligands to induce peroxisome elongation in our experimental system. Interestingly, they did not induce a pronounced peroxisome elongation in our experimental system. While the PPAR $\alpha$ agonist $\mathrm{Wy}-14,643$ and the PPAR $\gamma$ agonist troglitazone did induce some peroxisome elongation at the higher concentrations tested (Supplementary Figure 2), this was a significantly smaller effect than the FBSinduced elongation, suggesting PPAR activation alone is not sufficient to account for the proliferative effect of serum on peroxisomes, which is in line with the mild effects described for peroxisome proliferators on human cells. Furthermore, the PPAR $\gamma$ antagonist GW9962, which inhibits PPAR $\gamma$ binding to its binding elements (Liu et al., 2016), caused a small decrease in peroxisome elongation compared to controls, but did not occlude the peroxisome elongation/proliferation induced by serum. This implies that serum contains factors which can induce peroxisome elongation/proliferation independently of PPARs.

Apart from fatty acids, the stimulatory effect of serum on peroxisome dynamics and proliferation may be due to the involvement of growth factor-dependent pathways, such as the mTOR pathway. In order to investigate the involvement of the mTOR pathway in peroxisome elongation/proliferation in our assay, cells cultured in MEM/N1 medium were pretreated with the mTOR inhibitor rapamycin prior to serum stimulation. Two hours of rapamycin pre-treatment blocked 
A
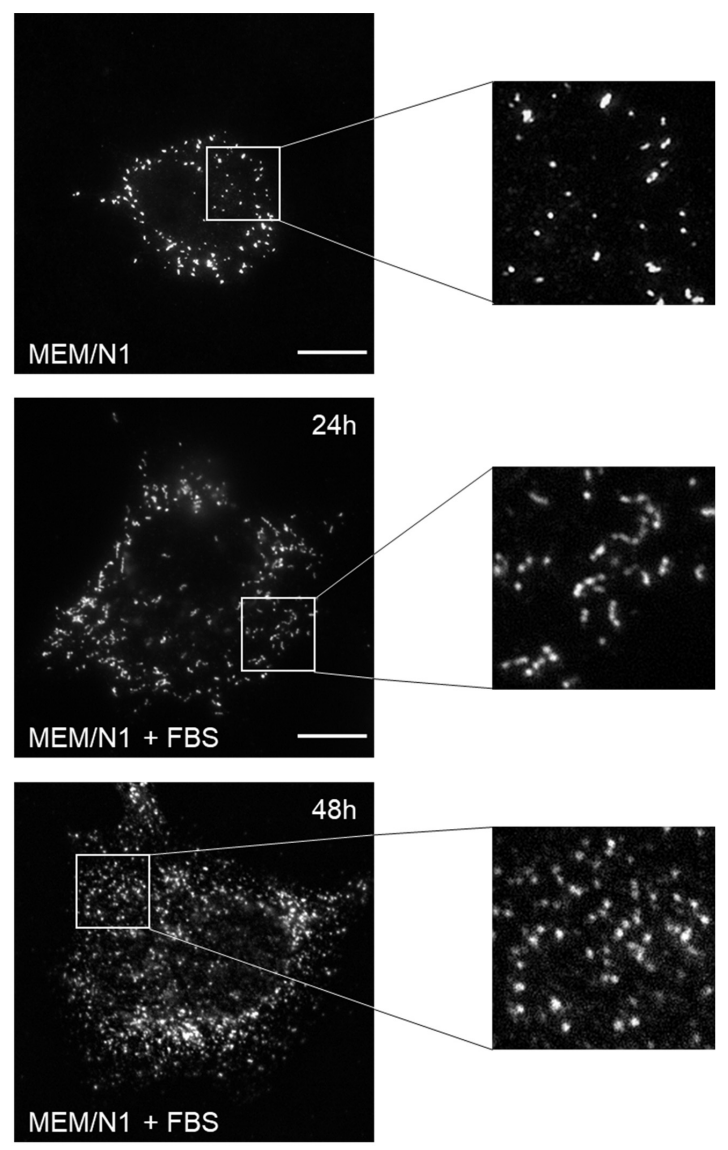

B

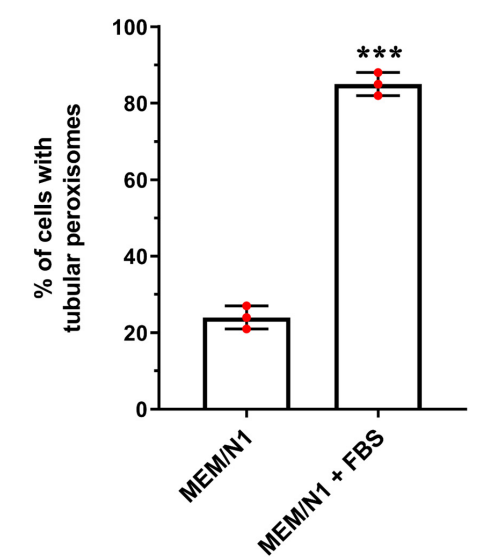

C

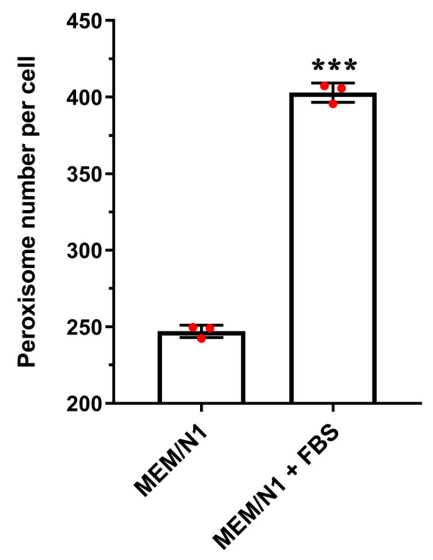

FIGURE 1 | Effect of serum on peroxisome morphology/proliferation in HepG2 cells. (A) Representative images of cells cultured in MEM/N1 and cells stimulated with $10 \%$ FBS (MEM/N1 + FBS). Cells were processed for immunofluorescence after 24 or 48 h of stimulation and stained with anti-PEX14 antibodies. Bars, $10 \mu \mathrm{m}$

(B) Quantitative analysis of peroxisome elongation after $24 \mathrm{~h}$, expressed as percentage of cells exhibiting tubular peroxisomes. Data from 3 independent experiments ( $n=300$ cells in each condition); analyzed by two-tailed unpaired $t$-test. (C) Quantitative analysis of peroxisome number per cell after 48 h. Data from 3 independent experiments ( $n=10$ cells for each condition), analyzed by two-tailed unpaired $t$-test; ${ }^{\star \star *} p<0.001$.

peroxisome elongation in response to serum stimulation in a dose-dependent manner (Figure 4B), supporting our hypothesis that growth factor-mediated signaling pathways (specifically, the mTOR pathway) may play a role in the initiation of peroxisome proliferation during cellular growth.

\section{Differential mRNA Profiles During Peroxisome Proliferation}

Little is known about the regulation of peroxins and peroxisomal membrane proteins and the relationship between gene expression and peroxisome proliferation, in particular in humans. The only peroxin whose expression has so far been linked to peroxisome proliferation in humans is PEX11 (Schrader et al., 2016). We therefore set out to profile which peroxisomal genes may be involved in peroxisomal growth and division by correlating their time-resolved mRNA expression profiles with distinct peroxisome proliferation events in our synchronized cell model. mRNA was extracted at given time points after serum-stimulated induction of peroxisome proliferation, corresponding to distinct phases in the elongation and division process (Schrader et al., 1998a) (Figure 3A) - at $6 \mathrm{~h}$, when peroxisome elongation begins; at 12 and $24 \mathrm{~h}$ when the number of elongated peroxisomes increases and peaks; and at 48 and $72 \mathrm{~h}$, when division of the elongated peroxisomes has occurred, and they return to their spherical shape. qPCR was used to quantify changes in relative mRNA levels of a number of candidate peroxisomal genes across these stages of proliferation, normalized to $18 \mathrm{~S}$ rRNA levels.

We first investigated the mRNA profiles of the three mammalian isoforms of PEX11 $(\alpha, \beta$, and $\gamma)$ during peroxisome proliferation, as these proteins are thought to be involved in the peroxisome growth and division cycle (Figure 3B). Interestingly, while PEX11 $\beta$ mRNA levels correlated well with the peroxisome proliferation cycle, PEX11 $\alpha$ and PEX11 $\gamma$ did not, with their mRNA levels declining over time. These findings support the view that PEX11 $\beta$ is the key PEX11 isoform promoting

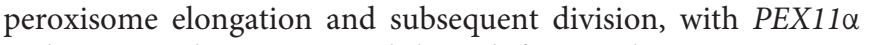
and PEX11 $\gamma$ playing more subtle or different roles.

Interestingly, mRNA levels of the early peroxins PEX3 and PEX19 were also observed to correlate with the peroxisome 
A
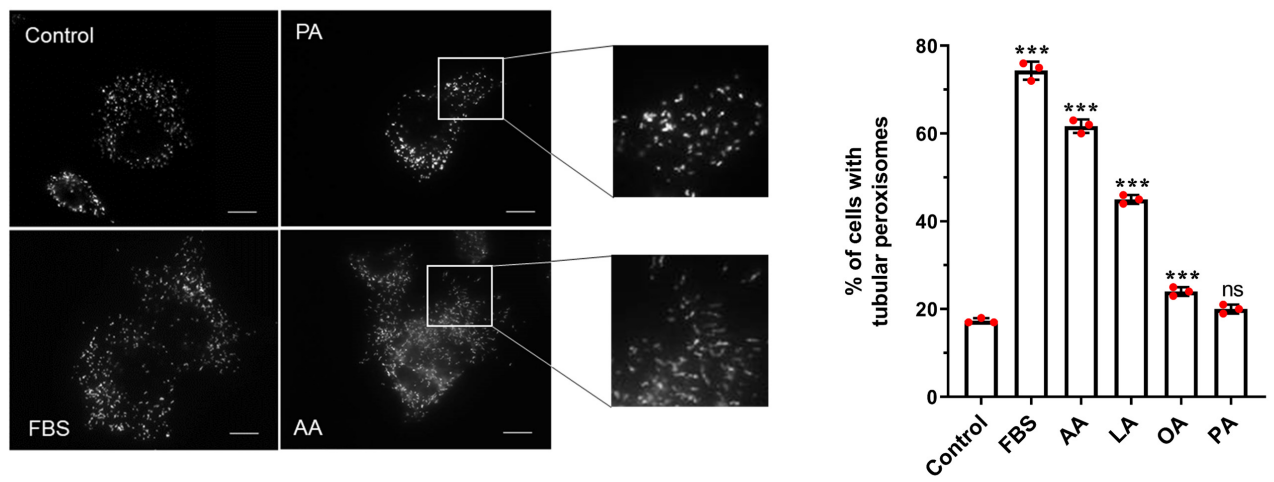

B
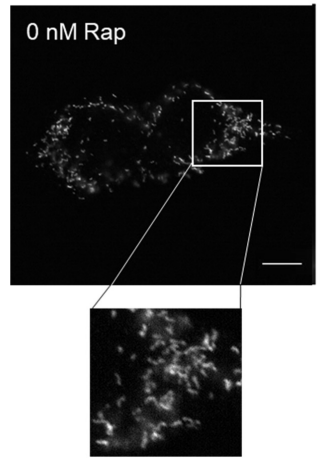
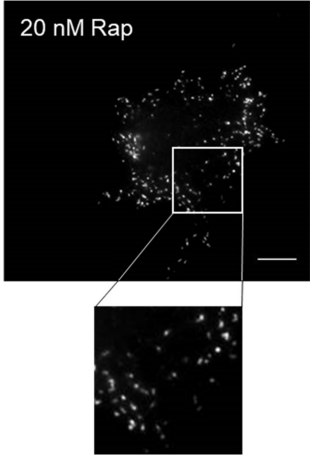

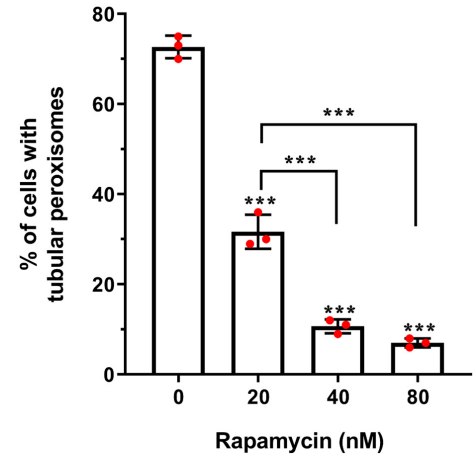

FIGURE 2 | Effect of fatty acids and rapamycin on peroxisome elongation in HepG2 cells. (A) Quantitative analysis of peroxisome morphology upon stimulation with $50 \mu \mathrm{M}$ fatty acids in HepG2 cells cultured in MEM/N1 for $24 \mathrm{~h}$. Note the strong stimulatory effect of PUFAs (AA and LA). (B) Quantitative analysis of peroxisome morphology after treatment of HepG2 cells with rapamycin and subsequent serum stimulation. Data in (A,B) are based on immunofluorescence microscopy using anti-PEX14 from 3 independent experiments ( $n=300$ cells in each condition); analyzed by one-way ANOVA with Dunnett's (A) or Tukey's (B) post hoc test; ${ }^{\star \star *} p<0.001$. AA, arachidonic acid; LA, linoleic acid; OA, oleic acid; PA, palmitic acid.

proliferation cycle, whereas PEX16 remained unchanged and declined at later time points (Figure 3B). As these early peroxins are required for the insertion of peroxisomal membrane proteins including PEX11 $\beta$, increased mRNA levels of those early peroxins is consistent with a requirement for PEX11 $\beta$ in proliferation. Other peroxins such as PEX2, PEX5, PEX10, PEX12, PEX13, and $P E X 14$, which are involved in peroxisomal matrix protein import, showed a variety of expression profiles: a minor increase in mRNA expression after $24 \mathrm{~h}$ followed by a decline (PEX10 and PEX14), a slight decline after $72 \mathrm{~h}$ (PEX2) or no change over the time course (PEX5, PEX12, and PEX13) (Figure 3B). Similarly, mRNA levels of the AAA-ATPase export complex components (PEX1, PEX6, and PEX26) did not correlate with the peroxisome proliferation cycle either, showing a minor increase after $24 \mathrm{~h}$ followed by a decline (PEX1), a decrease in expression after $48 \mathrm{~h}$ which recovers by $72 \mathrm{~h}(P E X 6)$ and a slight decline after $72 \mathrm{~h}$ (PEX26), respectively.

The mRNA profile of the transcription factors $P P A R \alpha$, $P P A R \gamma 1$, and $P G C 1 \alpha$, which are classically thought to be involved in the upregulation of peroxisomal matrix protein expression (in particular $\beta$-oxidation enzymes in rodents), did not correlate with peroxisomal morphology alterations, and expression of those transcription factors rather declined over time, or remained constant $(P G C 1 \alpha)$ (Figure 5A). These findings may indicate that the observed morphological alterations are independent of those transcription factors. It has, however, been reported that PPAR $\alpha$ expression is upregulated in HepG2 cells at the mRNA and protein level following prolonged incubation times in culture (Stier et al., 1998). Notably, mRNA levels of the transcription factor $P G C 1 \beta$ does seem to correlate with the peroxisome proliferation cycle, suggesting this could play a role in peroxisome elongation and/or division. Interestingly, mRNA levels of the peroxisomal $\mathrm{ABC}$ transporter $A B C D 3$ (PMP70) also followed the morphological changes of peroxisomes, whereas mRNA levels for $A B C D 1$, the $\mathrm{ABC}$ transporter for VLCFA, remained unchanged (Figure 5B). mRNA levels of $A C O X 1 a$ and $A C O X 1 b$, key enzymes in the first step of peroxisomal fatty acid $\beta$-oxidation, was slightly reduced over time, while mRNA levels of $E H H A D H$, which catalyzes the 2 nd and 3 rd step of peroxisomal $\beta$-oxidation, were upregulated after $24 \mathrm{~h}$, and expression of $A C A A 1$, which catalyzes the final step, was increased after 12 and $24 \mathrm{~h}$ but decreased after $72 \mathrm{~h}$ (Figure 5B). mRNA levels for other proteins required for peroxisomal $\beta$-oxidation, such as carnitine metabolism (CROT and $C R A T$ ), also follow different patterns over time, whereas the peroxisomal membrane protein PMP34 (cofactor transport) correlated with the peroxisome proliferation cycle. Furthermore, 


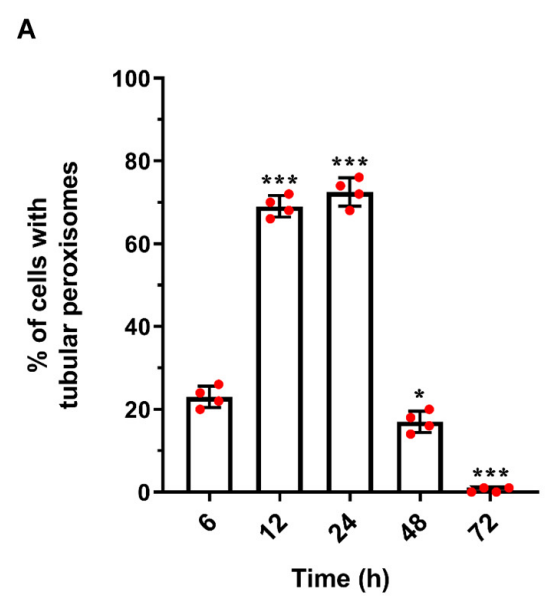

B
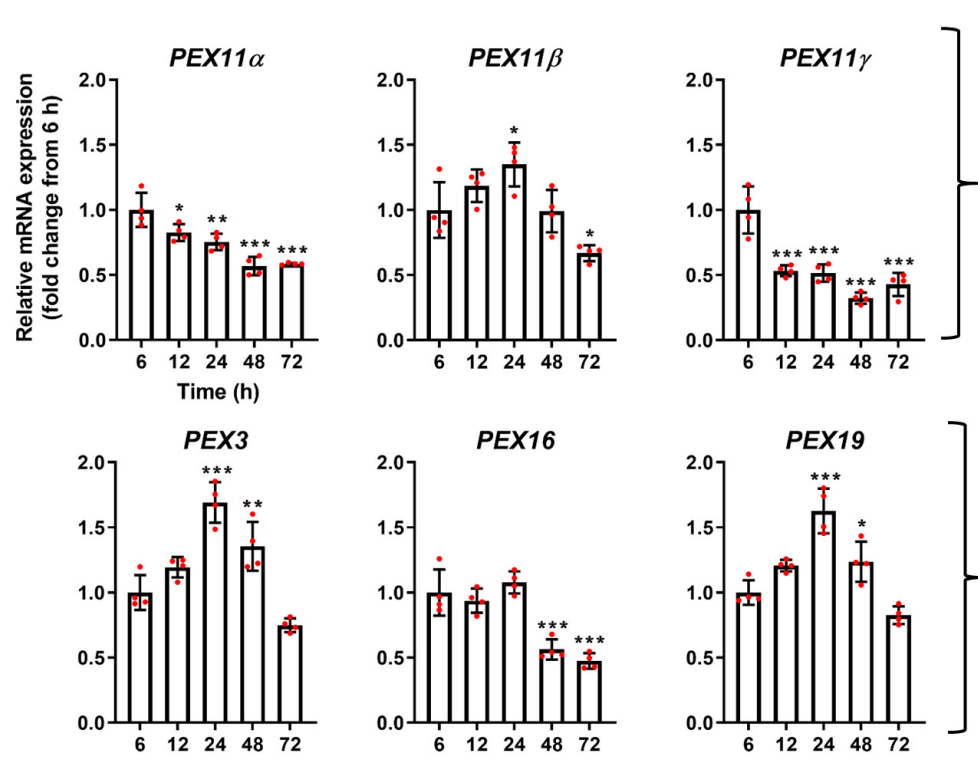

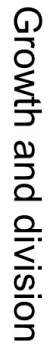
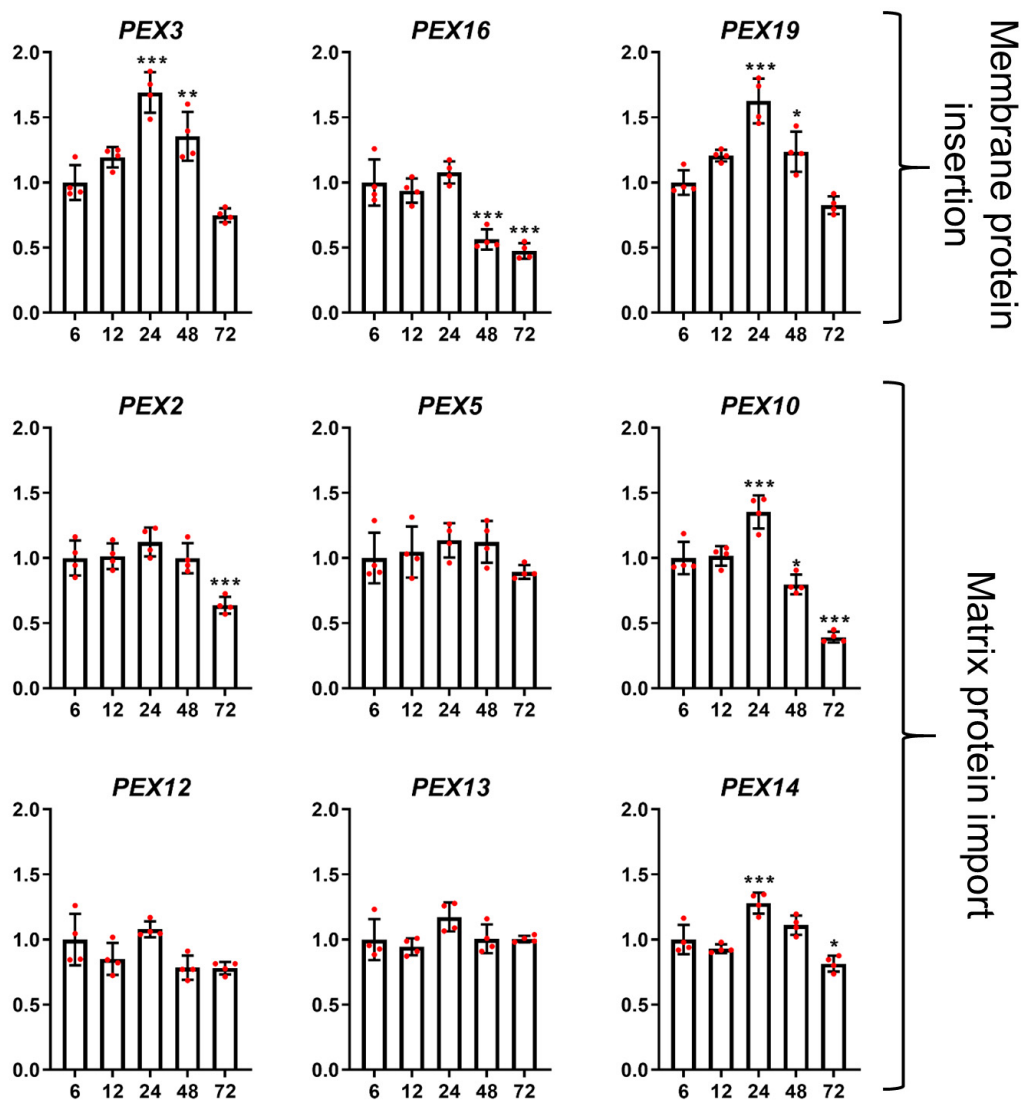

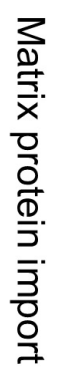
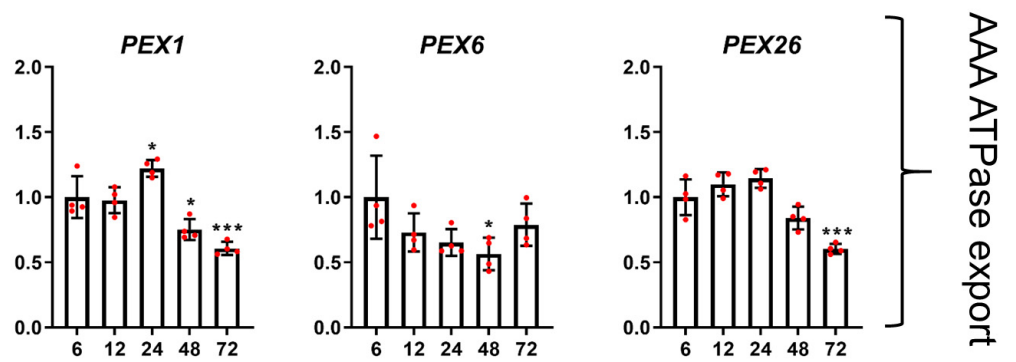

FIGURE 3 | Correlation of peroxisome morphology and mRNA abundance profiles of PEX genes in HepG2 cells during a time course. (A) Quantitative analysis of tubular peroxisomes in HepG2 cells monitored over time in MEM/FBS and processed for immunofluorescence. Data from 4 independent experiments $(n=300$ cells in each condition); analyzed by one-way ANOVA with Dunnett's post hoc test. (B) qPCR analysis of relative mRNA levels of a set of PEX genes normalized to 18S rRNA expression over time. Note that PEX11 $\beta$ mRNA levels correlate with the proportion of cells showing tubular peroxisome morphology, emphasizing its role in peroxisome elongation and division. In contrast, PEX11 a mRNA levels do not correlate with changes in peroxisome morphology. Data from 4 independent experiments; analyzed by one-way ANOVA with Dunnett's post hoc test; ${ }^{*} p<0.05,{ }^{* *} p<0.01,{ }^{* * *} p<0.001$. 

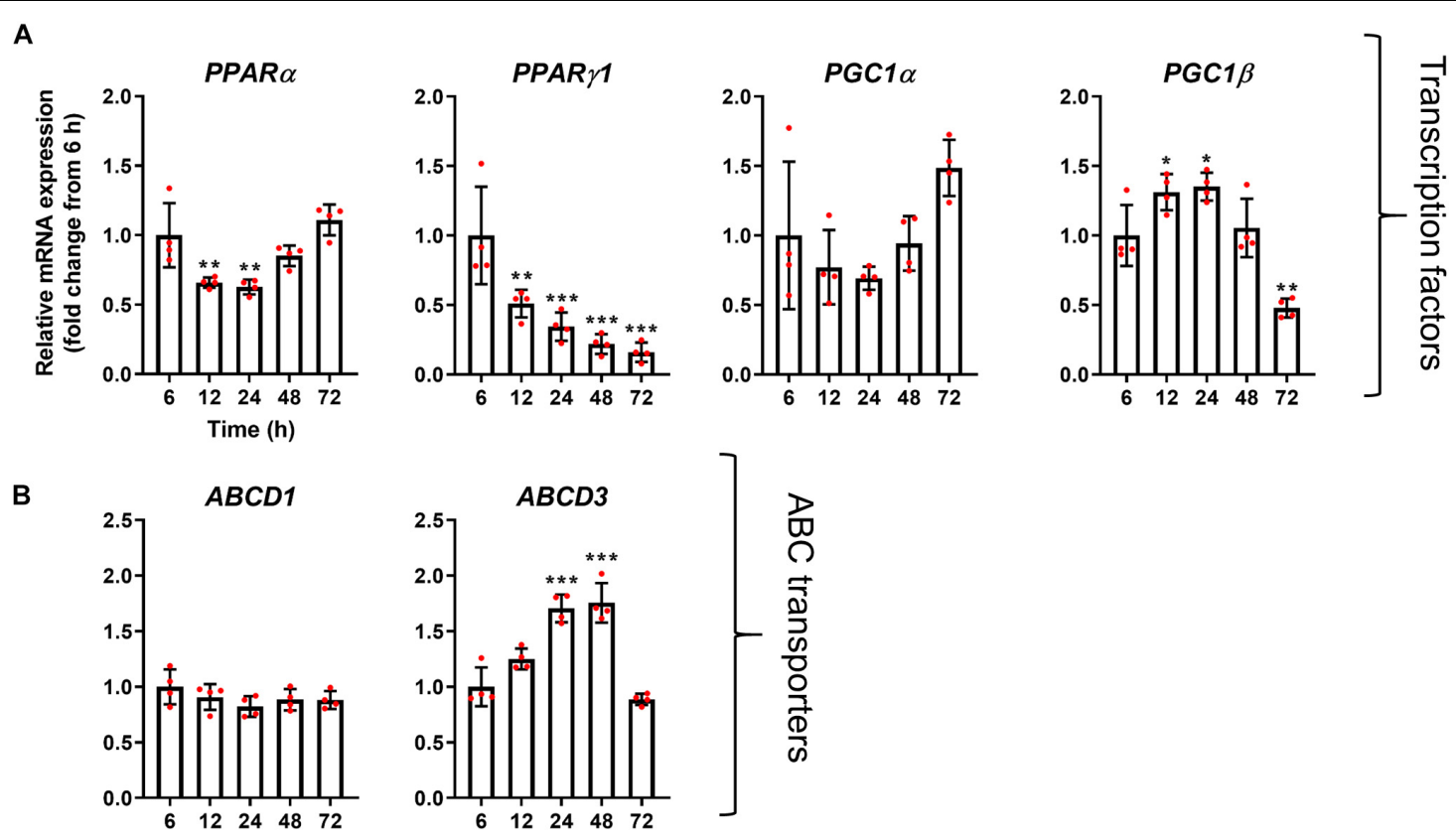

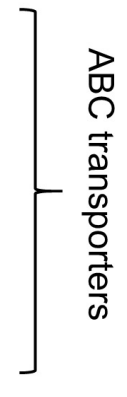
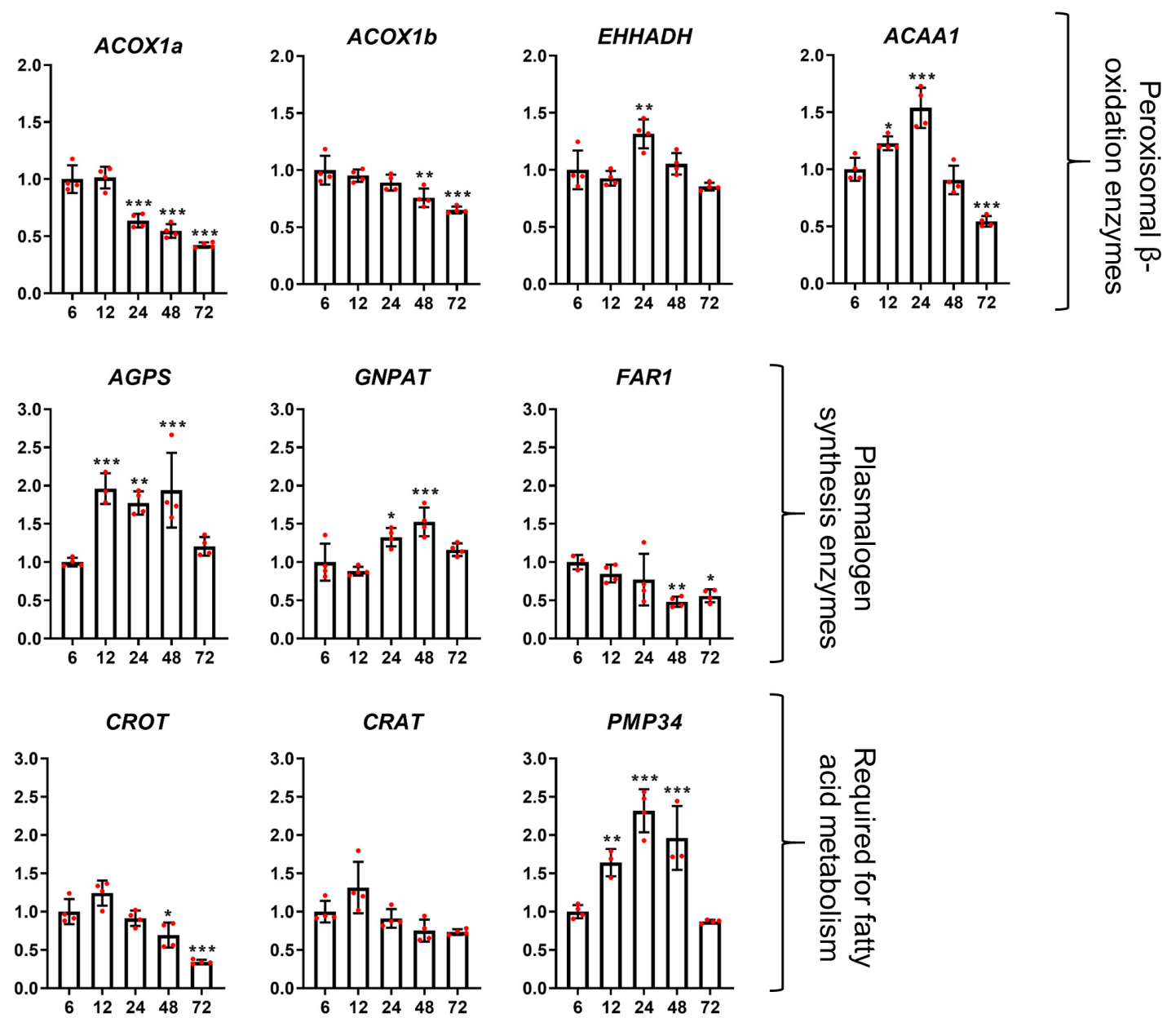

FIGURE 4 | mRNA abundance profiles of peroxisomal transcription factors/co-factors (A) and peroxisomal genes associated with fatty acid beta-oxidation (B) in HepG2 cells during a time course. qPCR analysis of relative mRNA levels of the indicated genes, normalized to $18 \mathrm{~S}$ rRNA expression over time. Data from 4 independent experiments; analyzed by one-way ANOVA with Dunnett's post hoc test; ${ }^{\star} p<0.05,{ }^{\star \star} p<0.01,{ }^{\star \star \star} p<0.001$. 

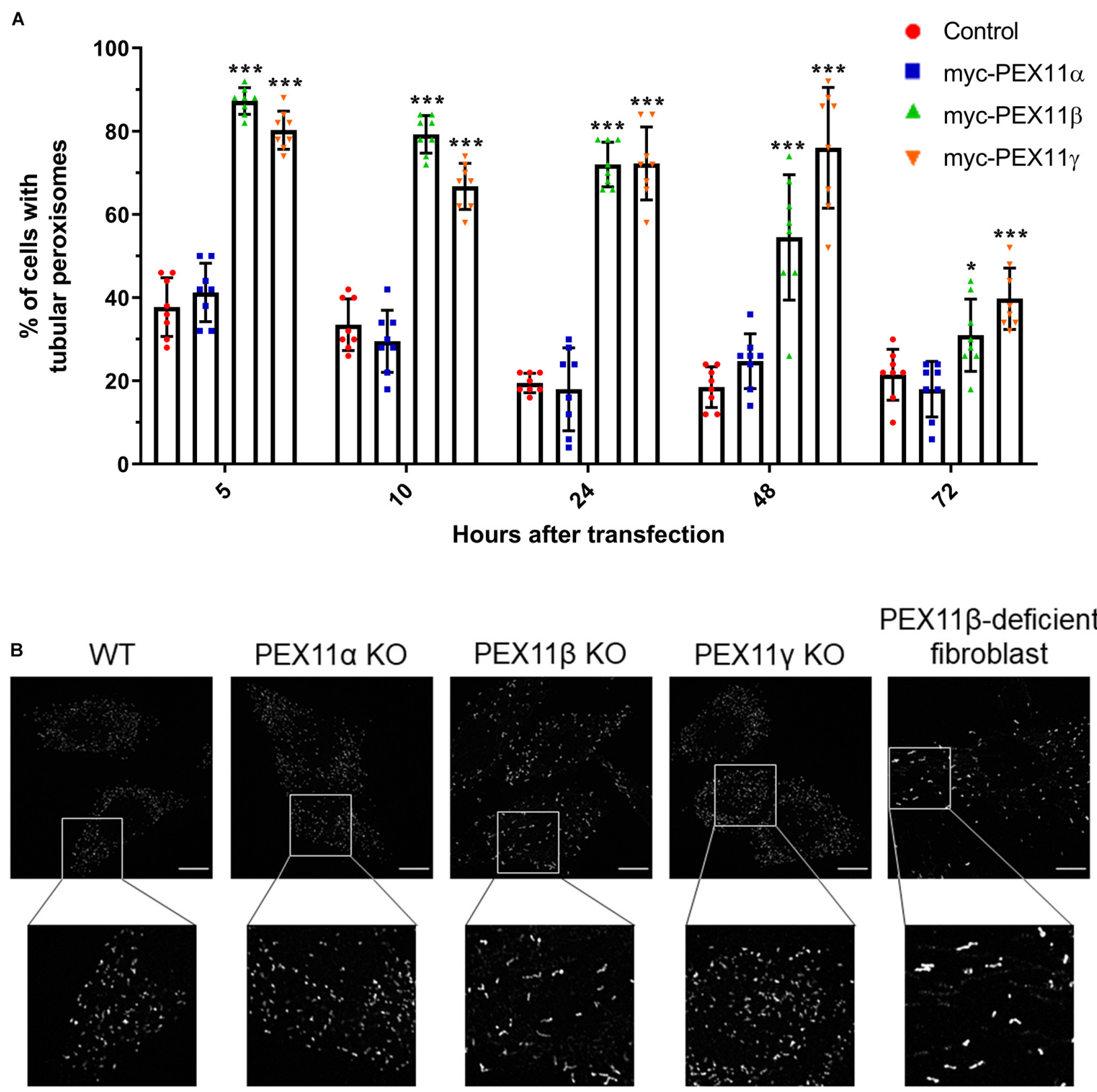

PEX11ß-deficient

FIGURE 5 | The human PEX11 isoforms affect peroxisome morphology differently. (A) Quantitative analysis of peroxisome morphologies in cells expressing different human PEX11 isoforms. COS-7 cells were transfected with Myc-PEX11 $\alpha$, Myc-PEX11 $\beta$, or Myc-PEX11 $\gamma$, processed for immunofluorescence using anti-Myc and anti-PEX14 antibodies at the indicated time points after transfection, and analyzed by microscopy. Note the prominent effect of Myc-PEX11 $\beta$ and Myc-PEX11 $\gamma$ on peroxisome elongation/division, in contrast to Myc-PEX11 $\alpha$ expression, which is similar to mock-transfected controls (Con). Data from 4 independent experiments; analyzed by one-way ANOVA with Dunnett's post hoc test for each time point; ${ }^{*} p<0.05$, ${ }^{\star * *} p<0.001$. (B) HeLa PEX11 KO cells and controls, and PEX11 $\beta$-deficient fibroblasts were processed for immunofluorescence microscopy using antibodies against PEX14. Note the reduced number and elongation of peroxisomes in the PEX11 $\beta$-deficient cells. Bars, $10 \mu \mathrm{m}$.

mRNA levels of peroxisomal enzymes involved in plasmalogen synthesis showed distinct profiles, either increasing (AGPS and GNPAT) or decreasing (FAR1) at later time points (Figure 5B). Together this suggests that, in some cases, peroxisomal genes that perform similar functions (e.g., enzymes involved in $\beta$-oxidation or plasmalogen synthesis) may be independently regulated during proliferation.

\section{The Mammalian PEX11 Isoforms Differ in Their Membrane Elongation-Inducing Properties}

Our results from the mRNA profiling during peroxisome proliferation suggested that the three human PEX11 isoforms may play different roles in the regulation of peroxisome 


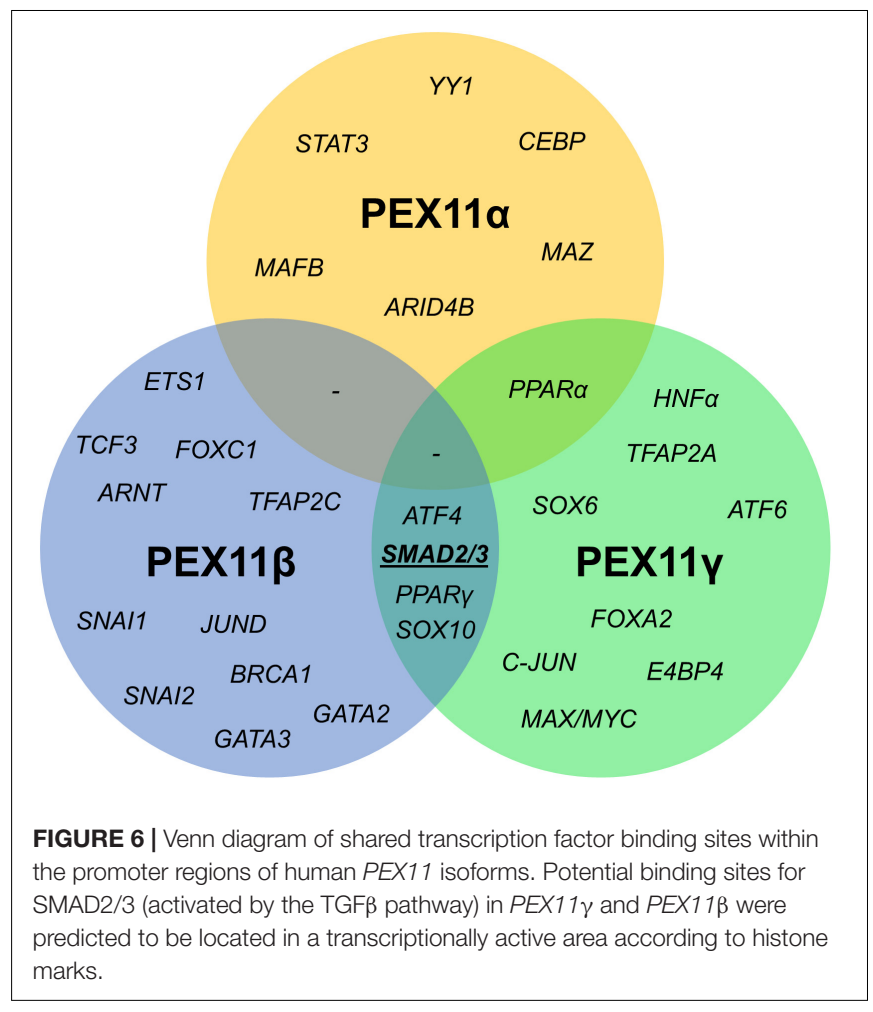

dynamics. In order to compare the functional effects of these isoforms on peroxisome morphology, COS-7 cells cultured in serum-containing media (to promote peroxisome growth and division) were transfected with Myc-PEX11 $\alpha$, Myc-PEX11 $\beta$, or Myc-PEX11 $\gamma$, processed for immunofluorescence after 5-72 h using anti-Myc and anti-PEX14 antibodies, and analyzed (Figure 6A). Quantification of peroxisome morphology revealed that overexpression of both Myc-PEX11 $\beta$ and Myc-PEX11 $\gamma$ had already induced the formation of tubular peroxisomes just $5 \mathrm{~h}$ after transfection. The number of cells with tubular peroxisomes declined over time, likely due to division of elongated peroxisomes into spherical organelles. In contrast, expression of Myc-PEX11 $\alpha$ did not induce peroxisome elongation, and values were similar to controls confirming previous studies in both HepG2 and COS-7 cells (Schrader et al., 1998b; Delille et al., 2010). These findings indicate that the PEX11 isoforms affect peroxisome morphology differently, with $\beta$ and $\gamma$ being capable of inducing peroxisome elongation, whereas $\alpha$ cannot.

We also analyzed peroxisome morphology in HeLa CRISPR knock out (KO) cells lacking PEX11 $\alpha$, PEX11 $\beta$, or PEX11 $\gamma$, cultured in serum-containing media. Immunofluorescence microscopy using anti-PEX14 antibodies revealed a spherical peroxisome morphology in PEX11 $\alpha$ and PEX11 $\gamma$ KO cells, which was comparable to controls (Figure 6B). In contrast, peroxisomes in PEX11 $\beta$ KO cells were reduced in number and showed a rodshaped, slightly elongated morphology (Figure 6B). A similar peroxisome morphology was observed in skin fibroblasts from patients with a loss of PEX11 $\beta$ (Figure 6B) (Ebberink et al., 2012). At first glance, the slightly elongated peroxisome morphology in PEX11 $\beta$-deficient cells may contradict the proposed function of
PEX11 $\beta$ as a driver of membrane elongation. However, PEX11 $\beta$ also plays a role in peroxisome division as it acts as a GTPase activating protein (GAP) on the fission GTPase DRP1 (Williams et al., 2015). We suggest that as a consequence of this GAP function, peroxisome division is reduced in the absence of PEX11 $\beta$ leading to a slight elongation of peroxisomes, perhaps mediated by PEX11 $\gamma$, which also has membrane elongating properties (Figure 6A) and can partially complement PEX11 $\beta$ (Ebberink et al., 2012).

\section{Promoter Analysis of the PEX11 Isoforms Suggests They Are Independently Regulated}

Since the mRNA profiles of the three PEX11 isoforms differed during the peroxisome proliferation/division cycle, we set out to identify candidate factors leading to this differential regulation. A comparison of the promoter regions of all three human PEX11 genes revealed that PEX11 $\beta$ and PEX11 $\gamma$ share four putative transcription factor binding sites for SMAD2/3 (Small worm phenotype/Mothers Against Decapentaplegic homolog 2/3), ATF4 (Activating Transcription Factor 4), SOX10 (Sexdetermining Region Y-related High Mobility Group-box 10) and PPAR $\gamma$. In contrast, no transcription factor binding sites are shared between PEX11 $\beta$ and PEX11 $\alpha$, while PEX11 $\alpha$ and $P E X 11 \gamma$ only share one binding site (for PPAR $\alpha$ ) (Figure 7). These findings indicate that $P E X 11 \beta$ and PEX11 $\alpha$ are likely to be differently regulated at a transcriptional level and further support our notion that both proteins fulfill different functions at peroxisomes.

\section{The Canonical TGF $\beta$ Pathway Is Involved in Peroxisome Proliferation in HepG2 Cells}

One of the key activators of SMAD2/3 is transforming growth factor beta (TGF $\beta$ ), via the canonical TGF $\beta$ signaling pathway. We chose to focus our subsequent studies on SMAD2/3-mediated regulation of PEX11 $\beta$ and the possible link between TGF $\beta$ signaling and peroxisome proliferation, as a proof-of-principle of our predictive promoter analysis. This was selected because of: (i) the functional role of PEX11 $\beta$ in peroxisome elongation and division (Figure 6); (ii) the high probability prediction of a SMAD2/3 binding site in the promoter region of PEX11 $\beta$ (Supplementary Table 6), and (iii) the ability of TGF $\beta$ to activate mTOR, a driver of peroxisome proliferation (Figure 4B), which together suggested that expression of PEX11 $\beta$, and thus peroxisome proliferation, might be linked to TGF $\beta$ signaling. First, we tested whether TGF $\beta$ could induce peroxisome elongation and proliferation in our cell-based model. HepG2 cells cultured in MEM/N1 were mock treated or treated with $2 \mathrm{ng} / \mathrm{ml}$ recombinant TGF $\beta$ for $24 \mathrm{~h}$ prior to fixation and PEX14 immunofluorescence (Figure 2). Recombinant TGF $\beta$ activates Type I and, indirectly, Type II TGF $\beta$ receptors on the cell surface, resulting in phosphorylation of the SMAD2/3 complex and its translocation to the nucleus where it can modulate transcription of target genes (Dituri et al., 2013). Whereas control cells showed overwhelmingly spherical peroxisomes, 
A
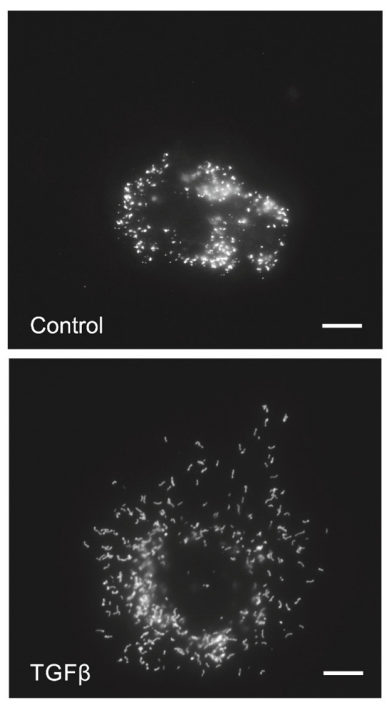

\section{FBS}
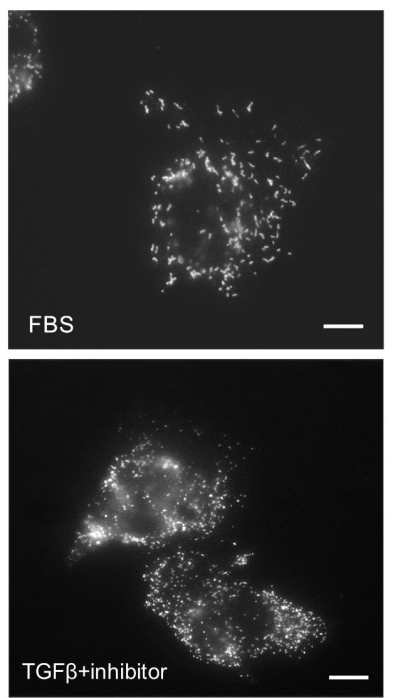

TGF $\beta$ +inhibitor

\section{B}

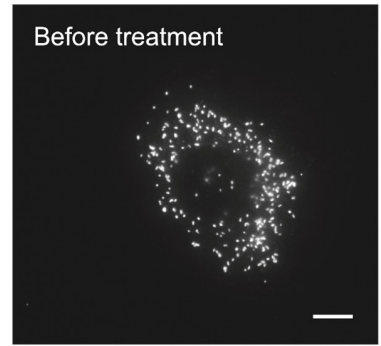

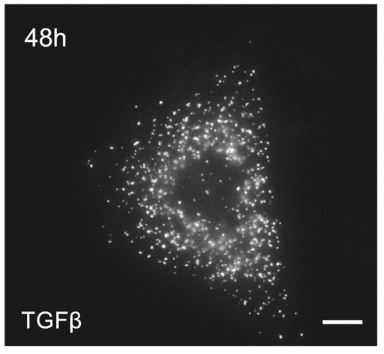
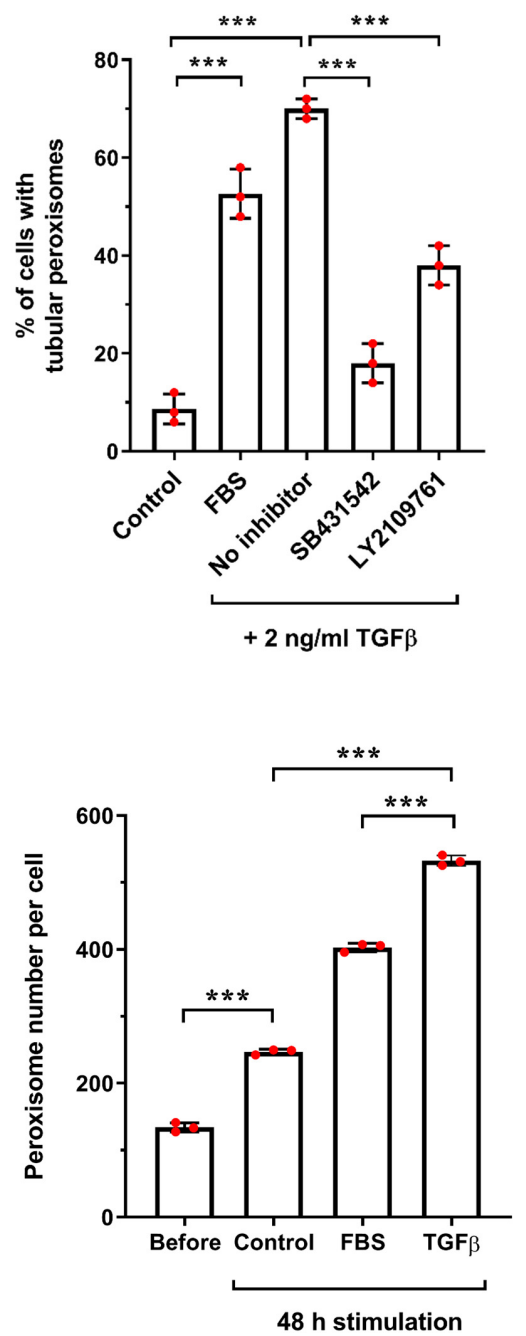

FIGURE 7 | TGF $\beta$ increases peroxisome elongation and number in HepG2 cells. (A) HepG2 cells were cultured in MEM/N1, treated with 10\% FBS, or TGF $\beta$ ( $2 \mathrm{ng} / \mathrm{ml}$ ) (with or without inhibitors LY2109761 or SB431542) or mock treated and processed for immunofluorescence after $24 \mathrm{~h}$ after treatment using anti-PEX14 antibodies. Representative images and quantitative analysis of peroxisome morphology (elongation) for the conditions described are shown. Data from 3 independent experiments ( $n=300$ cells for each condition); analyzed by one-way ANOVA with Tukey's post hoc test; ${ }^{\star * *} p<0.001$. Bars, $10 \mu \mathrm{m}$. (B) HepG2 cells were cultured in MEM/N1 for $6 \mathrm{~h}$ prior to the addition of TGF $\beta$ ( $2 \mathrm{ng} / \mathrm{ml}$ ) or $10 \%$ FBS, and processed for immunofluorescence after $6 \mathrm{~h}$ ('before' treatment) and $48 \mathrm{~h}$ after treatment as described in (A). Representative images and quantitative analysis of peroxisome number/cell before and $48 \mathrm{~h}$ are shown. Data from 3 independent experiments ( $n=10$ cells for each condition); analyzed by one-way ANOVA with Tukey's post hoc test; ${ }^{\star \star *} p<0.001$. Bars, $10 \mu \mathrm{m}$.

addition of TGF $\beta$ resulted in a pronounced elongation of peroxisomes, a pre-requisite of peroxisomal growth and division (Figure 2A). To validate that the effect was specific to the SMAD-mediated TGF $\beta$ pathway, we used specific chemical inhibitors which block the TGF $\beta$ signaling pathway. SB431542 selectively inhibits Type I TGF $\beta$ receptors by suppressing SMAD3 phosphorylation, whereas LY2109761 inhibits both Type I and II receptors, resulting in reduced phosphorylation of SMAD2 (Dituri et al., 2013). Pre-treatment of HepG2 cells with either inhibitor for $2 \mathrm{~h}$ before adding recombinant TGF $\beta$ reduced peroxisome elongation significantly when compared to TGF $\beta$-treated controls (Figure 2A) indicating a specific TGF $\beta$-mediated response. Furthermore, consistent with the effect of serum stimulation, the number of peroxisomes in TGF $\beta$-treated cells was significantly increased when compared to unstimulated controls (Figure 2B). $48 \mathrm{~h}$ TGF $\beta$ treatment resulted in an over two-fold increase in peroxisome numbers compared to untreated cells cultured for the same amount of time, which is indicative of accelerated peroxisome proliferation. Overall, these findings support a role for TGF $\beta$ signaling in peroxisome proliferation, potentially via SMAD2/3 binding to the PEX11 $\beta$ promoter.

To verify that transcription of PEX11 $\beta$ can be regulated by TGF $\beta$ in a SMAD-dependent manner, we transfected HepG2 cells with constructs consisting of a firefly luciferase reporter gene under the control of the PEX11 $\beta$ promoter, and assayed 
the effect of TGF $\beta$ on luminescence as a result of firefly luciferase expression (Figure 8). TGF $\beta$ treatment dramatically increased the expression of firefly luciferase driven by the wild type PEX11 $\beta$ promoter (or a control promoter with an optimized SMAD2/3 binding site, 'SMAD'), relative to a constitutively expressed, TK promoter-driven Renilla luciferase as an internal control. However, mutating the putative SMAD2/3 binding site in the PEX11 $\beta$ promoter ('mut') prevented the TGF $\beta$-dependent increase in reporter expression (Figure 8). These findings indicate that the SMAD2/3 binding site within the PEX11 $\beta$ promoter is functional, and that PEX11 $\beta$ transcription is positively regulated by TGF $\beta$ signaling via its SMAD2/3 binding site.

\section{DISCUSSION}

In this study, we used the well-differentiated human hepatoblastoma cell line HepG2 as a model system to assess the ability of different stimuli to induce peroxisome proliferation. The peroxisomal compartment in HepG2 cells is very dynamic, displaying high plasticity including the presence of elongated peroxisomes (Schrader et al., 1996; Grabenbauer et al., 2000). These elongated peroxisomes form by membrane expansion as a pre-requisite of peroxisome division and can be observed during rapid cellular growth, for example after hepatectomy (Yamamoto and Fahimi, 1987b) or in cultured mammalian cells (including COS-7 cells) (Schrader et al., 1996, 1998a; Duclos et al., 1997). Stimulation of cultured cells with defined growth factors, fatty acids or free radicals promotes peroxisome elongation (Schrader et al., 1998a, 1999) as does depolymerisation of microtubules (Schrader et al., 1996; Passmore et al., 2017), suggesting the involvement of intracellular signaling in peroxisome elongation. Motor-driven pulling forces, e.g., mediated by the kinesinadaptor Mirol along microtubules, can also contribute to peroxisomal membrane expansion (Castro et al., 2018) as well as inhibition of the peroxisomal division machinery (Koch et al., 2003; Gandre-Babbe and van der Bliek, 2008; Passmore et al., 2020) and tethering of peroxisomes to the ER (Costello et al., 2017).

We show here that peroxisome membrane expansion/elongation in HepG2 cells depends on serum/growth factors, and can be inhibited by rapamycin, an inhibitor of the mTOR pathway, the main growth factor-dependent pathway in mammalian cells (Wullschleger et al., 2006). Indeed, the mTOR pathway has recently been linked to peroxisome homeostasis and signaling (Zhang et al., 2013, 2015). Notably, the PPAR $\gamma$ antagonist GW9962 did not prevent the induction of peroxisome elongation by serum, while the PPAR $\alpha$ agonist Wy-14,643 and the PPAR $\gamma$ ligand troglitazone only had a relatively small stimulatory effect on peroxisome elongation, and to a lower extent than serum addition. These observations are in line with earlier studies (Sher et al., 1993; Stangl et al., 1995; Duclos et al., 1997; Schrader et al., 1998b; Hsu et al., 2001; Lawrence et al., 2001; Bagattin et al., 2010) and point to the involvement of PPAR-independent pathways in peroxisome elongation/proliferation in humans. In a high-content screen probing more than 15,000 drugs, 10 compounds were reported to induce peroxisome proliferation in HepG2 cells, which appear to be only mildly sensitive to PPAR $\alpha$-mediated peroxisome proliferation (Sexton et al., 2010).

A stimulatory effect of PUFAs, especially AA [C20:4 ( $\omega-6)]$ on peroxisomal membrane expansion confirms earlier studies (Schrader et al., 1998a). PA (C16:0), a preferential substrate for mitochondrial $\beta$-oxidation, was not effective in inducing elongation, supporting specificity for longer-chain/unsaturated fatty acids, which link to the synthesis of cellular lipid mediators. $\mathrm{AA}$ is the substrate for the synthesis of prostaglandins and leukotrienes. As peroxisomes are involved in the degradation of prostaglandins (Diczfalusy and Alexson, 1988; Schepers et al., 1988) and leukotrienes (Jedlitschky et al., 1991), peroxisome elongation/proliferation may help to balance intracellular levels of these eicosanoids. Furthermore, other PUFAs such as DHA [C22:6(n-3)] have previously been shown to mediate peroxisome elongation and division/proliferation (Itoyama et al., 2012). While PUFAs, including DHA, are well-characterized ligands of PPAR $\alpha$ (Krey et al., 1997), DHA-induced peroxisomal proliferation has been shown to be independent of PPAR $\alpha$ activation, but dependent on PEX11 $\beta$ and peroxisome division factors (Itoyama et al., 2012).

In line with this, PEX11 $\beta$ mRNA levels correlated well with peroxisome elongation and subsequent division/proliferation. PEX14 mRNA levels were also slightly upregulated after $24 \mathrm{~h}$ in culture, when peroxisomes were also most elongated. Besides a role in matrix protein import, PEX14 has also been suggested to function as a microtubule docking factor stabilizing elongated peroxisomes, which may explain its induction during proliferation (Bharti et al., 2011; Theiss et al., 2012; Castro et al., 2018; Passmore et al., 2020). mRNA levels of the peroxisomal $\mathrm{ABC}$ transporter $A B C D 3$ (PMP70) correlated with the peroxisome proliferation cycle in line with previous studies (Schrader et al., 1998a). mRNA levels for the transcription factor $P P A R \alpha$ or $A C O X 1$, a key enzyme in peroxisomal $\beta$-oxidation, did not correlate with the peroxisome proliferation cycle, which is perhaps surprising, as enzyme expression may be expected to rise in line with the increase in peroxisome number to maintain normal metabolism. However, mRNA and protein levels of $P P A R \alpha$ and branched-chain ACOX2 have been previously shown to only be markedly elevated at the later phases of longterm culture and differentiation of HepG2 cells, suggesting that peroxisome proliferation (investigated here) and peroxisome maturation, characterized by a metabolically-active phenotype once cells reach confluency, may be two distinct and differentially regulated processes (Stier et al., 1998). PGC1 $\alpha$ mRNA levels are also reported to increase after 3 days, and may link to an (differentiation-dependent) induction of peroxisomal activity (Bagattin et al., 2010; Huang et al., 2017).

We focussed on the function and regulation of the PEX11 proteins, which are supposed to be key regulators of peroxisome proliferation, although the functions of the different PEX11 isoforms in peroxisome proliferation are still controversial. They have been suggested to cooperate in the coordination of peroxisomal growth and division (Koch and Brocard, 2012), but functions in fatty acid oxidation, transport processes, organelle 


\section{A}

PEX11ßWT: CTG CTAAAT GGA TGAAGA GTC TCC TGA CCG GAG AGG

PEX11ßmut: CTG CTAAAT GGA TGAAGA _. C TCC TGA CCG GAG AGG

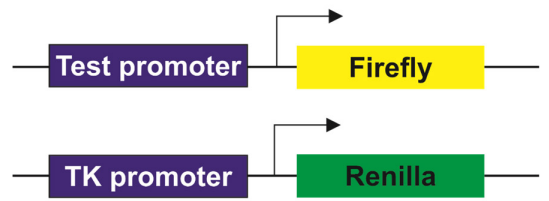

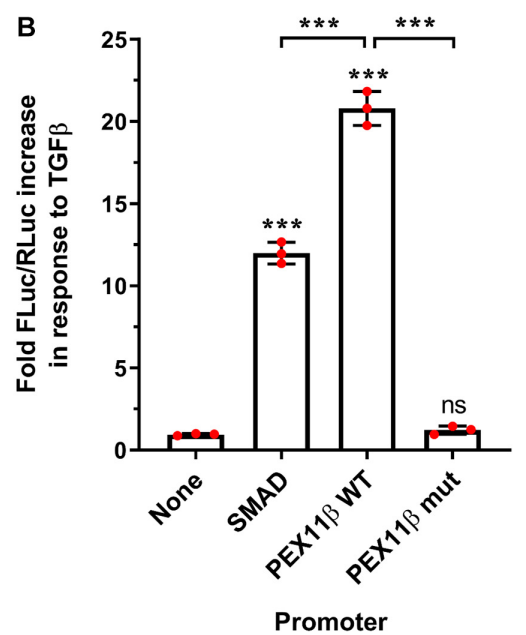

FIGURE 8 ITGF $\beta$ activates PEX11 $\beta$ expression by direct binding of the SMAD2/3 transcription factor to the PEX11 $\beta$ promoter. Luciferase reporter assays in HepG2 cells transfected with a Firefly-Luc reporter under the control of a SMAD2/3 motif-containing promoter ('SMAD'); or PEX11 $\beta$ wild type ('WT') or SMAD2/3 mutant ('mut') promoter. As a control, a promoter-less Firefly-Luc vector was used. Cells were treated with TGF $\beta(2 \mathrm{ng} / \mathrm{ml}$ ) or left untreated. (A) Schematic of the reporter vectors used. The potential SMAD2/3 binding motif (underlined) in the PEX11 $\beta$ promoter and the deleted base pairs are indicated. pRL-TK construct with thymidine kinase promoter upstream of Renilla luciferase was used as an internal control in all the experiments. (B) Quantitative analysis of the effect of TGF $\beta$ on promoter activity. Firefly luciferase activity (FLuc) was first normalized to Renilla luciferase activity (RLuc) in each condition. Fold increase in response to TGF $\beta$ was then calculated by normalizing the relative luminometer unit values for each construct in the presence of TGF $\beta$ to the value without TGF $\beta$. Data from 3 independent experiments; analyzed by one-way ANOVA with Tukey's post hoc test; ns non-significant, ${ }^{\star \star \star} p<0.001$.

interplay and membrane contacts have also been reported (van Roermund et al., 2000; Dulermo et al., 2015; Mattiazzi Ušaj et al., 2015; Mindthoff et al., 2016; Kustatscher et al., 2019; Wu et al., 2020).

Our data reveal that PEX11 $\beta$ and PEX11 $\alpha$ are likely to be differently regulated as different transcription factors are predicted to control their expression. Additionally, in contrast to PEX11 $\beta, P E X 11 \alpha$ mRNA levels did not follow the changes in peroxisome morphology in HepG2 cells. Furthermore, expression of PEX11 $\alpha$ did not induce peroxisome membrane expansion, which is consistent with previous studies (Schrader et al., 1998b; Delille et al., 2010). PEX11 $\alpha$ cannot complement loss of PEX11 $\beta$ (Ebberink et al., 2012), and despite their similar membrane topology, both proteins show different sensitivity to Triton-X 100 pointing to different functions and biochemical properties within the peroxisomal membrane (Schrader et al., 2012a). Patients suffering from PEX11 $\beta$ deficiency have been identified (Ebberink et al., 2012; Taylor et al., 2017; Tian et al., 2019), whereas patients with a defect in PEX11 $\alpha$ function have not yet been diagnosed. In line with this, knockout of PEX11 $\beta$ in mice is lethal, whereas PEX $11 \alpha \mathrm{KO}$ mice appear healthy (Li et al., 2002a,b). However, feeding of PEX11 $\alpha$ KO mice with a high-fat diet resulted in impaired physical activity and energy expenditure, decreased fatty acid $\beta$-oxidation, increased de novo lipogenesis as well as dyslipidaemia and obesity (Chen et al., 2019). Overall, these findings highlight that PEX $11 \alpha$ and PEX11 $\beta$ have different functions, and may support a role for PEX11 $\alpha$ in peroxisomal fatty acid metabolism rather than in peroxisome proliferation.

We confirmed that the identified putative SMAD2/3 binding site in the promoter region of PEX $11 \beta$ is functional and TGF $\beta$-responsive, and could potentially link peroxisome proliferation to the canonical, SMAD-dependent TGF $\beta$ signaling pathway in HepG2 cells. A stimulatory effect of TGF $\beta$ on peroxisome elongation, albeit less prominent due to altered experimental conditions, was observed in a previous study (Schrader et al., 1998a). Other genes containing putative SMAD2/3 binding sites include PEX11 $\gamma$, FIS1, PEX13 and PEX14 (Supplementary Table 6) further indicating the potential involvement of this pathway in the regulation of genes involved in peroxisome dynamics, and these genes may therefore also contribute to the TGF $\beta$-induced peroxisome proliferation, along with PEX11 $\beta$. Previous work has demonstrated a reduction in PEX13 and PEX14 expression in fibroblasts following TGF $\beta$ stimulation (Oruqaj et al., 2015), which is perhaps surprising given our data suggests TGF $\beta$ promotes peroxisome proliferation, and we find PEX13 mRNA stays the same, while PEX14 mRNA increases, during FBS-induced peroxisome proliferation (Figure 3). This could be a result of tissuespecific differences in the TGF $\beta$-dependent regulation of peroxisome proliferation, or differences in the regulation of PEX13 and PEX14 by serum factors as opposed/in addition to TGF $\beta$.

The TGF $\beta$ pathway is involved in the regulation of cellular proliferation, differentiation, embryogenesis, apoptosis, inflammation, immunity and cancer pathways (Massagué, 2012). TGF $\beta$ is also a key regulator of liver physiology and pathology. It contributes to hepatocyte proliferation and differentiation, but also to all stages of disease progression, from initial liver injury through inflammation and fibrosis to cirrhosis and hepatocellular carcinoma (Fabregat et al., 2016). HepG2 cells have been shown 
to express TGF $\beta$ and to respond to TGF $\beta$ treatment or silencing of TGF $\beta$ with alterations in cell growth, apoptosis and the cell cycle (Wang et al., 2017). We assume that TGF $\beta$ signaling in our experimental system contributes to the proliferation and/or differentiation of HepG2 cells as peroxisome elongation is a hallmark of cell growth and proliferation (Schrader et al., 1999). Interestingly, elongated and tubular or constricted peroxisomes were also observed after partial hepatectomy in rat liver (Yamamoto and Fahimi, 1987a). These heterogenous peroxisome morphologies were interpreted as an indicator of peroxisome proliferation by elongation/growth and division under conditions of cellular growth and proliferation (Schrader and Fahimi, 2008). TGF $\beta$ has a crucial role in hepatocytes in vivo, being critical for the control of liver mass (Karkampouna et al., 2012). The TGF $\beta$ pathway has activator and repressor effects on other pathways such as cell growth, so balanced TGF $\beta$ signaling in terms of both dosage and spatiotemporal activity is crucial to control hepatic gene expression. TGF $\beta$ acts in the process of differentiation of hepatoblasts to hepatocytes during liver regeneration after partial hepatectomy (Karkampouna et al., 2012). The TGF $\beta$ pathway is required at different stages of the process, to allow hepatocyte proliferation at the inductive phase followed by an efficient termination of the regenerative response afterward.

Since HepG2 cells are hepatoblastoma cells, which can differentiate in culture and form bile canaliculi-like structures (Bokhari et al., 2007), we propose that, similar to regenerating liver, TGF $\beta$ induces peroxisome proliferation in HepG2 cells under proliferative culture conditions, possibly via upregulation of PEX11 $\beta$, a key regulator of peroxisomal growth and multiplication. Under standard culture conditions, peroxisome elongation has a maximum after $24-48 \mathrm{~h}$, before the elongated peroxisomes divide resulting in the formation of numerous spherical peroxisomes. Peroxisomes do not massively elongate at later time points in culture, when the cells are more confluent, and therefore growing more slowly (Schrader et al., 1998a). Ultrastructural studies have shown that at prolonged culture the peroxisomes in HepG2 cells are larger and form small clusters of organelles, possibly changing from a proliferative to a metabolic state (Grabenbauer et al., 2000). As PEX11 $\beta$ mediates peroxisome elongation and proliferation, it represents an ideal target to adapt peroxisome number and function according to cellular needs. TGF $\beta$ signaling may foster peroxisome proliferation in an inductive phase of HepG2/hepatocyte proliferation and differentiation, but may also reduce proliferation of peroxisomes afterward, when the inductive stage is completed, and cell growth needs to be terminated. As TGF $\beta$ signaling is complex, it is likely that other, non-canonical signaling pathways as well as TGF $\beta$ secretion, the concentration of active TGF $\beta$, and the amount of TGF $\beta$ receptors and spatiotemporal activity, contribute to the overall cellular response. Additionally, PEX11 $\beta$ expression is likely to be subject to other levels of regulation, such as translational control or alterations in protein stability, localization or activity, that coordinate to fine-tune peroxisome proliferation in response to various conditions, which is an interesting avenue for future investigation.

\section{CONCLUSION}

We reveal a new TGF $\beta$-dependent signaling pathway controlling peroxisome proliferation which may act by regulating $P E X 11 \beta$ gene expression. This opens a possibility for therapeutic approaches controlling regulation of $P E X 11 \beta$ in patients where peroxisome abundance/activity is reduced.

\section{DATA AVAILABILITY STATEMENT}

All datasets generated for this study are included in the article/Supplementary Material.

\section{AUTHOR CONTRIBUTIONS}

AA, RC, WK, JK, and SK performed experiments and analyzed the data. MS, WK, and $\mathrm{HW}$ conceived the project and analyzed data. MS and RC wrote the manuscript. All authors contributed to methods.

\section{FUNDING}

This work was supported by the Biotechnology and Biological Sciences Research Council (BBSRC) (BB/R016844/1, to MS), the Swiss National Science Foundation (SNSF) (31003A_166245, to WK), and the European Union's FP7 Research and Innovation Programme under the Marie Skłodowska-Curie grant agreement no. 316723 PERFUME (to MS and HW). AA was supported by the Marie Skłodowska-Curie grant agreement no. 316723 PERFUME. SK was supported by the GW4 BioMed MRC Doctoral Training Partnership (MR/N0137941/1).

\section{ACKNOWLEDGMENTS}

We would like to acknowledge the support of T. A. Schrader and J. Costello (cell culture and molecular cloning), D. Devos (bioinformatics) and K. Falkenberg (experimental work at AMC). The research data supporting this publication are provided within this paper and as Supplementary Information.

\section{SUPPLEMENTARY MATERIAL}

The Supplementary Material for this article can be found online at: https://www.frontiersin.org/articles/10.3389/fcell.2020. 577637/full\#supplementary-material

Supplementary Figure 1 | Cellular growth curve based on cell number at the indicated time points. An exponential increase in cell density is observed in both cells cultured in MEM/N1 and MEM/FBS. Data are expressed as mean total cell number (per well) from 3 independent experiments. Measurements were performed in triplicate.

Supplementary Figure 2 | Effect of PPAR agonists and antagonists on peroxisome morphology in HepG2 cells. Quantitative analysis of peroxisome morphology in HepG2 cells cultured in MEM/N1 after treatment with the PPAR $\alpha$ agonist Wy-14,643 (10-20 $\mu \mathrm{M})$ (A), the PPAR $y$ agonist Troglitazone (5-15 $\mu \mathrm{M})$ 
(B), or pre-treatment with the PPAR $\gamma$ antagonist GW9962 $(20 \mu \mathrm{M})$ prior to serum stimulation (C). Treatment with FBS served as a positive control. Note that the PPAR $\gamma$ agonist Troglitazone and the PPAR $\alpha$ agonist $W y-14,643$ induce peroxisome elongation to a lesser extent than FBS. Furthermore, the PPAR $\gamma$ antagonist GW9962 does not repress serum-induced peroxisome elongation/proliferation. Data are based on immunofluorescence microscopy performed $24 \mathrm{~h}$ after treatment using anti-PEX14, from 3 independent experiments ( $n=300$ cells in each condition); analyzed by one-way ANOVA (A,B) or two-way ANOVA (C) with Tukey's post hoc test; ${ }^{* *} p<0.01,{ }^{* * *} p<0.001$.

Supplementary Table 1 | Details of plasmids used in this study.

\section{REFERENCES}

Bagattin, A., Hugendubler, L., and Mueller, E. (2010). Transcriptional coactivator PGC-1alpha promotes peroxisomal remodeling and biogenesis. Proc. Natl. Acad. Sci. U.S.A. 107, 20376-20381. doi: 10.1073/pnas.1009176107

Bharti, P., Schliebs, W., Schievelbusch, T., Neuhaus, A., David, C., Kock, K., et al. (2011). PEX14 is required for microtubule-based peroxisome motility in human cells. J. Cell Sci. 124, 1759-1768. doi: 10.1242/jcs.079368

Bokhari, M., Carnachan, R. J., Cameron, N. R., and Przyborski, S. A. (2007). Culture of HepG2 liver cells on three dimensional polystyrene scaffolds enhances cell structure and function during toxicological challenge. J. Anat. 211, 567-576. doi: 10.1111/j.1469-7580.2007.00778.x

Bonekamp, N. A., Vormund, K., Jacob, R., and Schrader, M. (2010). Dynamin-like protein 1 at the Golgi complex: a novel component of the sorting/targeting machinery en route to the plasma membrane. Exp. Cell Res. 316, 3454-3467. doi: 10.1016/j.yexcr.2010.07.020

Braverman, N. E., Raymond, G. V., Rizzo, W. B., Moser, A. B., Wilkinson, M. E., and Stone, E. M. (2016). Peroxisome biogenesis disorders in the Zellweger spectrum: an overview of current diagnosis, clinical manifestations, and treatment guidelines. Mol. Genet. Metab. 117, 313-321. doi: 10.1016/j. ymgme.2015.12.009

Castro, I. G., Richards, D. M., Metz, J., Costello, J. L., Passmore, J. B., Schrader, T. A., et al. (2018). A role for mitochondrial Rho GTPase 1 (MIRO1) in motility and membrane dynamics of peroxisomes. Traffic 19, 229-242. doi: 10.1111/tra. 12549

Chen, C., Wang, H., Chen, B., Chen, D., Lu, C., Li, H., et al. (2019). Pex1la deficiency causes dyslipidaemia and obesity in mice. J. Cell. Mol. Med. 23, 2020-2031. doi: $10.1111 /$ jcmm.14108

Cimini, A., Moreno, S., D’Amelio, M., Cristiano, L., D’Angelo, B., Falone, S., et al. (2009). Early biochemical and morphological modifications in the brain of a transgenic mouse model of Alzheimer's disease: a role for peroxisomes. J. Alzheimers. Dis. 18, 935-952. doi: 10.3233/JAD-2009-1199

Costello, J. L., Castro, I. G., Hacker, C., Schrader, T. A., Metz, J., Zeuschner, D., et al. (2017). ACBD5 and VAPB mediate membrane associations between peroxisomes and the ER. J. Cell Biol. 216, 331-342. doi: 10.1083/jcb.201607055

Delille, H. K., Agricola, B., Guimaraes, S. C., Borta, H., Lüers, G. H., Fransen, M., et al. (2010). Pex1lpbeta-mediated growth and division of mammalian peroxisomes follows a maturation pathway. J. Cell Sci. 123, 2750-2762. doi: $10.1242 /$ jcs.062109

Desai, M., and Hu, J. (2008). Light induces peroxisome proliferation in Arabidopsis seedlings through the photoreceptor phytochrome A, the transcription factor HY5 HOMOLOG, and the peroxisomal protein PEROXIN11b. Plant Physiol. 146, 1117-1127. doi: 10.1104/pp.107.113555

Desai, M., Pan, R., and Hu, J. (2017). Arabidopsis forkhead-associated domain protein 3 negatively regulates peroxisome division. J. Integr. Plant Biol. 59, 454-458. doi: 10.1111/jipb.12542

Diczfalusy, U., and Alexson, S. E. (1988). Peroxisomal chain-shortening of prostaglandin F2 alpha. J. Lipid Res. 29, 1629-1636.

Dituri, F., Mazzocca, A., Peidrò, F. J., Papappicco, P., Fabregat, I., De Santis, F., et al. (2013). Differential inhibition of the TGF- $\beta$ signaling pathway in HCC cells using the small molecule inhibitor LY2157299 and the D10 monoclonal antibody against TGF- $\beta$ Receptor Type II. PLoS One 8:e67109. doi: 10.1371/ journal.pone.0067109
Supplementary Table 2 | Plasmids generated in this study.

Supplementary Table 3 | Human qPCR primers used in this study.

Supplementary Table 4 | Primary and secondary antibodies used in this study.

Supplementary Table 5 | Generation of PEX11-deficient HeLa cells.

Supplementary Table 6 | Predicted SMAD2/3 binding sites in peroxisomal gene promoters. Start and end position expressed in relation to $10 \mathrm{~kb}$ region upstream of the transcription start site. Binding efficiency calculated from the SMAD2/3 JASPAR position-weight matrix consensus sequence (ID MA0513.1).

Dubois, V., Eeckhoute, J., Lefebvre, P., and Staels, B. (2017). Distinct but complementary contributions of PPAR isotypes to energy homeostasis. J. Clin Invest. 127, 1202-1214. doi: 10.1172/JCI88894

Duclos, S., Bride, J., Ramirez, L. C., and Bournot, P. (1997). Peroxisome proliferation and beta-oxidation in $\mathrm{Fao}$ and $\mathrm{MH} 1 \mathrm{Cl}$ rat hepatoma cells, HepG2 human hepatoblastoma cells and cultured human hepatocytes: effect of ciprofibrate. Eur. J. Cell Biol. 72, 314-323.

Dulermo, R., Dulermo, T., Gamboa-Meléndez, H., Thevenieau, F., and Nicaud, J.M. (2015). Role of Pex11p in lipid homeostasis in Yarrowia lipolytica. Eukaryot. Cell 14, 511-525. doi: 10.1128/EC.00051-15

Ebberink, M. S., Koster, J., Visser, G., Spronsen, F., Van Stolte-Dijkstra, I., Smit, G. P. A., et al. (2012). A novel defect of peroxisome division due to a homozygous non-sense mutation in the PEX11beta gene. J. Med. Genet. 49, 307-313. doi: 10.1136/jmedgenet-2012-100778

Fabregat, I., Moreno-Càceres, J., Sánchez, A., Dooley, S., Dewidar, B., Giannelli, G., et al. (2016). TGF- $\beta$ signalling and liver disease. FEBS J. 283, 2219-2232. doi: $10.1111 /$ febs.13665

Fransen, M., and Lismont, C. (2018). Redox signaling from and to peroxisomes: progress, challenges, and prospects. Antioxid. Redox Signal 30, 95-112. doi: 10.1089/ars.2018.7515

Fransen, M., Nordgren, M., Wang, B., and Apanasets, O. (2012). Role of peroxisomes in ROS/RNS-metabolism: implications for human disease. Biochim. Biophys. Acta 1822, 1363-1373. doi: 10.1016/j.bbadis.2011.12.001

Gandre-Babbe, S., and van der Bliek, A. M. (2008). The novel tail-anchored membrane protein Mff controls mitochondrial and peroxisomal fission in mammalian cells. Mol. Biol. Cell 19, 2402-2412. doi: 10.1091/mbc.E07

Grabenbauer, M., Sätzler, K., Baumgart, E., and Fahimi, H. D. (2000). Threedimensional ultrastructural analysis of peroxisomes in HepG2 Cells. Cell Biochem. Biophys. 32, 37-49. doi: 10.1385/cbb:32:1-3:37

Grant, P., Ahlemeyer, B., Karnati, S., Berg, T., Stelzig, I., Nenicu, A., et al. (2013). The biogenesis protein PEX14 is an optimal marker for the identification and localization of peroxisomes in different cell types, tissues, and species in morphological studies. Histochem. Cell Biol. 140, 423-442. doi: 10.1007/s00418013-1133-6

Grygiel-Górniak, B. (2014). Peroxisome proliferator-activated receptors and their ligands: nutritional and clinical implications - a review. Nutr. J. 13:17. doi: 10.1186/1475-2891-13-17

Hariharan, R., and Pillai, M. R. (2008). Structure-function relationship of inhibitory Smads: structural flexibility contributes to functional divergence. Proteins 71, 1853-1862. doi: 10.1002/prot.21869

Hill, C. S. (2016). Transcriptional control by the SMADs. Cold Spring Harb. Perspect. Biol. 8:a022079. doi: 10.1101/cshperspect.a022079

Horbelt, D., Denkis, A., and Knaus, P. (2012). A portrait of Transforming Growth Factor $\beta$ superfamily signalling: background matters. Int. J. Biochem. Cell Biol. 44, 469-474. doi: 10.1016/j.biocel.2011.12.013

Hsu, M. H., Savas, U., Griffin, K. J., and Johnson, E. F. (2001). Identification of peroxisome proliferator-responsive human genes by elevated expression of the peroxisome proliferator-activated receptor alpha in HepG2 cells. J. Biol. Chem. 276, 27950-27958. doi: 10.1074/jbc.M100258200

Huang, T.-Y., Zheng, D., Houmard, J. A., Brault, J. J., Hickner, R. C., and Cortright, R. N. (2017). Overexpression of PGC-1 $\alpha$ increases peroxisomal activity and mitochondrial fatty acid oxidation in human primary myotubes. Am. J. Physiol. Endocrinol. Metab. 312, E253-E263. doi: 10.1152/ajpendo.00331.2016 
Islinger, M., Cardoso, M. J. R. J. R., and Schrader, M. (2010). Be different-the diversity of peroxisomes in the animal kingdom. Biochim. Biophys. Acta 1803, 881-897. doi: 10.1016/j.bbamcr.2010.03.013

Itoyama, A., Honsho, M., Abe, Y., Moser, A., Yoshida, Y., Fujiki, Y., et al. (2012). Docosahexaenoic acid mediates peroxisomal elongation, a prerequisite for peroxisome division. J. Cell Sci. 125, 589-602. doi: 10.1242/jcs.087452

Itoyama, A., Michiyuki, S., Honsho, M., Yamamoto, T., Moser, A., Yoshida, Y., et al. (2013). Mff functions with Pex11p and DLP1 in peroxisomal fission. Biol. Open 2, 998-1006. doi: 10.1242/bio.20135298

Jedlitschky, G., Huber, M., Volkl, A., Muller, M., Leier, I., Muller, J., et al. (1991). Peroxisomal degradation of leukotrienes by beta-oxidation from the omegaend. J. Biol. Chem. 266, 24763-24772.

Kamato, D., Burch, M. L., Piva, T. J., Rezaei, H. B., Rostam, M. A., Xu, S., et al. (2013). Transforming growth factor- $\beta$ signalling: role and consequences of Smad linker region phosphorylation. Cell. Signal. 25, 2017-2024. doi: 10.1016/ j.cellsig.2013.06.001

Karkampouna, S., Ten Dijke, P., Dooley, S., and Julio, M. K. (2012). TGF $\beta$ signaling in liver regeneration. Curr. Pharm. Des. 18, 4103-4113. doi: 10.2174/ 138161212802430521

Kersten, S., and Stienstra, R. (2017). The role and regulation of the peroxisome proliferator activated receptor alpha in human liver. Biochimie 136, 75-84. doi: 10.1016/j.biochi.2016.12.019

Kintscher, U., Lyon, C., Wakino, S., Bruemmer, D., Feng, X., Goetze, S., et al. (2002). PPARalpha inhibits TGF-beta-induced beta5 integrin transcription in vascular smooth muscle cells by interacting with Smad4. Circ. Res. 91, e35-e44. doi: 10.1161/01.res.0000046017.96083.34

Kitisin, K., Saha, T., Blake, T., Golestaneh, N., Deng, M., Kim, C., et al. (2007), TGF-Beta signaling in development. Sci. STKE 2007:cm1. doi: 10.1126/stke. $3992007 \mathrm{cml}$

Kliewer, S. A., Umesono, K., Noonan, D. J., Heyman, R. A., and Evans, R. M. (1992). Convergence of 9-cis retinoic acid and peroxisome proliferator signalling pathways through heterodimer formation of their receptors. Nature 358, 771774. doi: $10.1038 / 358771 \mathrm{a} 0$

Koch, A., Thiemann, M., Grabenbauer, M., Yoon, Y., McNiven, M. A., and Schrader, M. (2003). Dynamin-like protein 1 is involved in peroxisomal fission. J. Biol. Chem. 278, 8597-8605. doi: 10.1074/jbc.M211761200

Koch, A., Yoon, Y., Bonekamp, N. A., Mcniven, M. A., and Schrader, M. (2005). A role for Fis1 in both mitochondrial and peroxisomal fission in mammalian cells. Mol. Biol. Cell 16, 5077-5086. doi: 10.1091/mbc.E05

Koch, J., and Brocard, C. (2012). PEX11 proteins attract Mff and human Fis1 to coordinate peroxisomal fission. J. Cell Sci. 125, 3813-3826. doi: 10.1242/jcs. 102178

Krey, G., Braissant, O., L'Horset, F., Kalkhoven, E., Perroud, M., Parker, M. G., et al. (1997). Fatty acids, eicosanoids, and hypolipidemic agents identified as ligands of peroxisome proliferator-activated receptors by coactivatordependent receptor ligand assay. Mol. Endocrinol. 11, 779-791. doi: 10.1210/ mend.11.6.0007

Kustatscher, G., Grabowski, P., Schrader, T. A., Passmore, J. B., Schrader, M., and Rappsilber, J. (2019). Co-regulation map of the human proteome enables identification of protein functions. Nat. Biotechnol. 37, 1361-1371. doi: 10.1038/ s41587-019-0298-5

la Cour Poulsen, L., Siersbæk, M., and Mandrup, S. (2012). PPARs: fatty acid sensors controlling metabolism. Semin. Cell Dev. Biol 23, 631-639. doi: 10.1016/ j.semcdb.2012.01.003

Lawrence, J. W., Li, Y., Chen, S., DeLuca, J. G., Berger, J. P., Umbenhauer, D. R., et al. (2001). Differential gene regulation in human versus rodent hepatocytes by peroxisome proliferator-activated receptor (PPAR) $\alpha$. PPAR $\alpha$ fails to induce peroxisome proliferation-associated genes in human cells independently of the level of receptor expression. J. Biol. Chem. 276, 31521-31527. doi: 10.1074/jbc. M103306200

Lazarow, P. B., and De Duve, C. (1976). A fatty acyl CoA oxidizing system in rat liver peroxisomes; enhancement by clofibrate, a hypolipidemic drug. Proc. Natl. Acad. Sci. U.S.A. 73, 2043-2046. doi: 10.1073/pnas.73.6.2043

Li, X., Baumgart, E., Dong, G.-X., Morrell, J. C., Jimenez-Sanchez, G., Valle, D., et al. (2002a). PEX11\$ $\$$ alpha $\{\backslash \$\}$ Is required for peroxisome proliferation in response to 4-phenylbutyrate but is dispensable for peroxisome proliferatoractivated receptor alpha-mediated peroxisome proliferation. Mol. Cell. Biol. 22, 8226-8240. doi: $10.1128 / \mathrm{mcb} .22 .23 .8226-8240.2002$
Li, X., Baumgart, E., Morrell, J. C., Jimenez-Sanchez, G., Valle, D., and Gould, S. J. (2002b). PEX11\$ $\backslash$ beta $\{\backslash \$$ Deficiency is lethal and impairs neuronal migration but does not abrogate peroxisome function. Mol. Cell. Biol. 22, 4358-4365. doi: $10.1128 / \mathrm{mcb} .22 .12 .4358-4365.2002$

Liu, X., Yu, Z., Huang, X., Gao, Y., Wang, X., Gu, J., et al. (2016). Peroxisome proliferator-activated receptor $\gamma(\operatorname{PPAR} \gamma)$ mediates the protective effect of quercetin against myocardial ischemia-reperfusion injury via suppressing the NF-кB pathway. Am. J. Transl. Res. 8, 5169-5186.

Massagué, J. (2012). TGF $\beta$ signalling in context. Nat. Rev. Mol. Cell Biol. 13, 616-630. doi: 10.1038/nrm3434

Mattiazzi Ušaj, M., Brložnik, M., Kaferle, P., Žitnik, M., Wolinski, H., Leitner, F., et al. (2015). Genome-wide localization study of yeast Pex11 identifies peroxisome-mitochondria interactions through the ERMES complex. J. Mol. Biol. 427, 2072-2087. doi: 10.1016/j.jmb.2015.03.004

Mindthoff, S., Grunau, S., Steinfort, L. L., Girzalsky, W., Hiltunen, J. K., Erdmann, R., et al. (2016). Peroxisomal Pex11 is a pore-forming protein homologous to TRPM channels. Biochim. Biophys. Acta 1863, 271-283. doi: 10.1016/j.bbamcr. 2015.11.013

Miyazawa, K., and Miyazono, K. (2017). Regulation of TGF- $\beta$ Family signaling by inhibitory smads. Cold Spring Harb. Perspect. Biol. 9:a022095. doi: 10.1101/ cshperspect.a022095

Nagaraj, N. S., and Datta, P. K. (2010). Targeting the transforming growth factorbeta signaling pathway in human cancer. Expert Opin. Investig. Drugs 19, 77-91. doi: 10.1517/13543780903382609

Nguyen, T., Bjorkman, J., Paton, B. C., and Crane, D. I. (2006). Failure of microtubule-mediated peroxisome division and trafficking in disorders with reduced peroxisome abundance. J. Cell Sci. 119, 636-645. doi: 10.1242/jcs. 02776

Opaliński, Ł, Kiel, J. A. K. W., Williams, C., Veenhuis, M., and van der Klei, I. J. (2011). Membrane curvature during peroxisome fission requires Pex11. EMBO J. 30, 5-16. doi: 10.1038/emboj.2010.299

Oruqaj, G., Karnati, S., Vijayan, V., Kotarkonda, L. K., Boateng, E., Zhang, W., et al. (2015). Compromised peroxisomes in idiopathic pulmonary fibrosis, a vicious cycle inducing a higher fibrotic response via TGF- $\beta$ signaling. Proc. Natl. Acad. Sci. U.S.A. 112, E2048-E2057. doi: 10.1073/pnas.1415111112

Passmore, J. B., Carmichael, R. E., Schrader, T. A., Godinho, L. F., Ferdinandusse, S., Lismont, C., et al. (2020). Mitochondrial fission factor (MFF) is a critical regulator of peroxisome maturation. Biochim. Biophys. Acta. Mol. Cell Res. 1867:118709. doi: 10.1016/j.bbamcr.2020.118709

Passmore, J. B., Pinho, S., Gomez-Lazaro, M., and Schrader, M. (2017). The respiratory chain inhibitor rotenone affects peroxisomal dynamics via its microtubule-destabilising activity. Histochem. Cell Biol. 148, 331-341. doi: 10. 1007/s00418-017-1577-1

Rakhshandehroo, M., Knoch, B., Michael, M., and Kersten, S. (2010). Peroxisome proliferator-activated receptor alpha target genes. PPAR Res. 2010:612089. doi: $10.1155 / 2010 / 612089$

Ran, F. A., Hsu, P. D., Wright, J., Agarwala, V., Scott, D. A., and Zhang, F. (2013). Genome engineering using the CRISPR-Cas9 system. Nat. Protoc. 8, 2281-2308. doi: 10.1038/nprot.2013.143

Schepers, L., Casteels, M., Vamecq, J., Parmentier, G., Van Veldhoven, P. P., and Mannaerts, G. P. (1988). Beta-oxidation of the carboxyl side chain of prostaglandin E2 in rat liver peroxisomes and mitochondria. J. Biol. Chem. 263, 2724-2731.

Schneider, C. A., Rasband, W. S., and Eliceiri, K. W. (2012). NIH Image to ImageJ: 25 years of image analysis. Nat. Methods 9, 671-675. doi: 10.1038/nmeth.2089

Schrader, M., Almeida, M., and Grille, S. (2012a). Postfixation detergent treatment liberates the membrane modelling protein Pexl1beta from peroxisomal membranes. Histochem. Cell Biol. 138, 541-547. doi: 10.1007/s00418-0121010-8

Schrader, M., Bonekamp, N. A., and Islinger, M. (2012b). Fission and proliferation of peroxisomes. Biochim. Biophys. Acta 1822, 1343-1357. doi: 10.1016/j.bbadis. 2011.12.014

Schrader, M., Burkhardt, J. K., Baumgart, E., Lüers, G. H., Spring, H., Volkl, A., et al. (1996). Interaction of microtubules with peroxisomes. Tubular and spherical peroxisomes in HepG2 cells and their alteractions induced by microtubule-active drugs. Eur. J. Cell Biol. 69, 24-35.

Schrader, M., Castro, I., Fahimi, H. D., and Islinger, M. (2014). "Peroxisome morphology in pathologies," in Molecular Machines Involved in Peroxisome 
Biogenesis and Maintenance, eds C. Brocard and A. Hartig (Berlin: Springer), 125-151. doi: 10.1007/978-3-7091-1788-0_7

Schrader, M., Costello, J. L., Godinho, L. F., Azadi, A. S., and Islinger, M. (2016). Proliferation and fission of peroxisomes - An update. Biochim. Biophys. Acta Mol. Cell Res. 1863, 971-983. doi: 10.1016/j.bbamcr.2015.09.024

Schrader, M., and Fahimi, H. D. (2006). Growth and division of peroxisomes. Int. Rev. Cytol. 255, 237-290. doi: 10.1016/s0074-7696(06)55005-3

Schrader, M., and Fahimi, H. D. (2008). The peroxisome: still a mysterious organelle. Histochem. Cell Biol. 129, 421-440. doi: 10.1007/s00418-008-0396-9

Schrader, M., Krieglstein, K., and Fahimi, H. D. (1998a). Tubular peroxisomes in HepG2 cells: selective induction by growth factors and arachidonic acid. Eur. J. Cell Biol. 75, 87-96. doi: 10.1016/S0171-9335(98)80051-4

Schrader, M., Reuber, B. E., Morrell, J. C., Jimenez-Sanchez, G., Obie, C., Stroh, T. A., et al. (1998b). Expression of PEX11beta mediates peroxisome proliferation in the absence of extracellular stimuli. J. Biol. Chem. 273, 2960729614. doi: 10.1074/jbc.273.45.29607

Schrader, M., Wodopia, R., and Fahimi, H. D. (1999). Induction of tubular peroxisomes by uv irradiation and reactive oxygen species in HepG2 Cells. J. Histochem. Cytochem. 47, 1141-1148. doi: 10.1177/002215549904700906

Sexton, J. Z., He, Q., Forsberg, L. J., and Brenman, J. E. (2010). High content screening for non-classical peroxisome proliferators. Int. J. High Throughput Screen 2010, 127-140. doi: 10.2147/IJHTS.S10547

Sher, T., Yi, H. F., McBride, O. W., and Gonzalez, F. J. (1993). cDNA cloning, chromosomal mapping, and functional characterization of the human peroxisome proliferator activated receptor. Biochemistry 32, 5598-5604. doi: 10.1021/bi00072a015

Shimizu, M., Takeshita, A., Tsukamoto, T., Gonzalez, F. J., and Osumi, T. (2004). Tissue-selective, bidirectional regulation of PEX11 and perilipin genes through a common peroxisome proliferator response element. Mol. Cell. Biol. 24, 1313-1323. doi: $10.1128 / \mathrm{mcb} \cdot 24.3 .1313-1323.2004$

Sohn, E. J., Kim, J., Hwang, Y., Im, S., Moon, Y., and Kang, D. M. (2012). TGF$\beta$ suppresses the expression of genes related to mitochondrial function in lung A549 cells. Cell. Mol. Biol. Suppl. 58, OL1763-OL1767.

Stangl, H., Kovacs, W., Bock, P., and Kremser, K. (1995). Differential induction of peroxisomal enzymes by hypolipidaemics in human (HepG2) and rat (MH1C1) hepatoma cell lines. Eur. J. Clin. Chem. Clin. Biochem. 33, 775-783. doi: 10.1515/ cclm.1995.33.11.775

Stier, H., Fahimi, H. D., Völkl, A., Baumgart, E., Van Veldhoven, P. P., and Mannaerts, G. P. (1998). Maturation of peroxisomes in differentiating human hepatoblastoma cells (HepG2): possible involvement of the peroxisome proliferator-activated receptor $\alpha$ (PPAR $\alpha)$. Differentiation 64, 55-66. doi: 10. 1046/j.1432-0436.1998.6410055.x

Taylor, R. L., Handley, M. T., Waller, S., Campbell, C., Urquhart, J., Meynert, A. M., et al. (2017). Novel PEX11B mutations extend the peroxisome biogenesis disorder 14B phenotypic spectrum and underscore congenital cataract as an early feature. Invest. Ophthalmol. Vis. Sci. 58, 594-603. doi: 10.1167/iovs.1621026

Theiss, C., Neuhaus, A., Schliebs, W., and Erdmann, R. (2012). TubStain: a universal peptide-tool to label microtubules. Histochem. Cell Biol. 138, 531-540. doi: 10.1007/s00418-012-0992-6

Tian, Y., Zhang, L., Li, Y., Gao, J., Yu, H., Guo, Y., et al. (2019). Variant analysis of PEX11B gene from a family with peroxisome biogenesis disorder $14 \mathrm{~B}$ by whole exome sequencing. Mol. Genet. Genomic Med. 8:mgg3.1042. doi: 10.1002/mgg3. 1042

Titorenko, V. I., and Terlecky, S. R. (2011). Peroxisome metabolism and cellular aging. Traffic 12, 252-259. doi: 10.1111/j.1600-0854.2010.01144.x

Tontonoz, P., and Spiegelman, B. M. (2008). Fat and beyond: the diverse biology of PPAR $\gamma$. Annu. Rev. Biochem. 77, 289-312. doi: 10.1146/annurev.biochem.77. 061307.091829

van der Meer, D. L. M., Degenhardt, T., Väisänen, S., de Groot, P. J., Heinäniemi, M., de Vries, S. C., et al. (2010). Profiling of promoter occupancy by PPAR $\alpha$ in human hepatoma cells via ChIP-chip analysis. Nucleic Acids Res. 38, 2839-2850. doi: 10.1093/nar/gkq012

van Heeringen, S. J., and Veenstra, G. J. C. (2010). GimmeMotifs: a de novo motif prediction pipeline for ChIP-sequencing experiments. Bioinformatics 27, 270-271. doi: 10.1093/bioinformatics/btq636

van Roermund, C. W., Tabak, H. F., van Den Berg, M., Wanders, R. J., and Hettema, E. H. (2000). Pex1lp plays a primary role in medium-chain fatty acid oxidation, a process that affects peroxisome number and size in Saccharomyces cerevisiae. J. Cell Biol. 150, 489-498. doi: 10.1083/jcb.150.3.489

Varga, T., Czimmerer, Z., and Nagy, L. (2011). PPARs are a unique set of fatty acid regulated transcription factors controlling both lipid metabolism and inflammation. Biochim. Biophys. Acta Mol. Basis Dis. 1812, 1007-1022. doi: 10.1016/j.bbadis.2011.02.014

Wanders, R. J. A. (2013a). Metabolic functions of peroxisomes in health and disease. Biochimie 98, 36-44. doi: 10.1016/j.biochi.2013.08.022

Wanders, R. J. A. (2013b). Peroxisomes in human health and disease: metabolic pathways, metabolite transport, interplay with other organelles and signal transduction. Sub Cell.Biochem. 69, 23-44. doi: 10.1007/978-94-007-6889-5_2

Wang, X.-H., Chen, Z.-G., Xu, R.-L., Lv, C.-Q., Liu, J., and Du, B. (2017). TGF$\beta 1$ signaling pathway serves a role in HepG2 cell regulation by affecting the protein expression of PCNA, gankyrin, p115, XIAP and survivin. Oncol. Lett. 13, 3239-3246. doi: 10.3892/ol.2017.5814

Williams, C., Opalinski, L., Landgraf, C., Costello, J., Schrader, M., Krikken, A. M., et al. (2015). The membrane remodeling protein Pex1lp activates the GTPase Dnm1p during peroxisomal fission. Proc. Natl. Acad. Sci. U.S.A. 112, 6377-6382. doi: 10.1073/pnas.1418736112

Wu, F., de Boer, R., Krikken, A. M., Akşit, A., Bordin, N., Devos, D. P., et al. (2020). Pex24 and Pex32 are required to tether peroxisomes to the ER for organelle biogenesis, positioning and segregation. J. Cell Sci. 133:jcs246983. doi: $10.1242 /$ jcs. 246983

Wullschleger, S., Loewith, R., and Hall, M. N. (2006). TOR signaling in growth and metabolism. Cell 124, 471-484. doi: 10.1016/j.cell.2006.01.016

Yadav, H., Quijano, C., Kamaraju, A. K., Gavrilova, O., Malek, R., Chen, W., et al. (2011). Protection from obesity and diabetes by blockade of TGF- $\beta /$ Smad3 signaling. Cell Metab. 14, 67-79. doi: 10.1016/j.cmet.2011.04.013

Yamamoto, K., and Fahimi, H. D. (1987a). Biogenesis of peroxisomes in regenerating rat liver. I. Sequential changes of catalase and urate oxidase detected by ultrastructural cytochemistry. Eur. J. Cell Biol. 43, 293-300.

Yamamoto, K., and Fahimi, H. D. (1987b). Three-dimensional reconstruction of a peroxisomal reticulum in regenerating rat liver: evidence of interconnections between heterogeneous segments. J. Cell Biol. 105, 713-722. doi: 10.1083/jcb. 105.2.713

Zhang, J., Kim, J., Alexander, A., Cai, S., Tripathi, D. N., Dere, R., et al. (2013). A tuberous sclerosis complex signalling node at the peroxisome regulates mTORC1 and autophagy in response to ROS. Nat. Cell Biol. 15, 1-13. doi: $10.1038 / \mathrm{ncb} 2822$

Zhang, J., Tripathi, D. N., Jing, J., Alexander, A., Kim, J., Powell, R. T., et al. (2015). ATM functions at the peroxisome to induce pexophagy in response to ROS. Nat. Cell Biol. 17, 1259-1269. doi: 10.1038/ncb3230

Conflict of Interest: The authors declare that the research was conducted in the absence of any commercial or financial relationships that could be construed as a potential conflict of interest.

Copyright $\odot 2020$ Azadi, Carmichael, Kovacs, Koster, Kors, Waterham and Schrader. This is an open-access article distributed under the terms of the Creative Commons Attribution License (CC BY). The use, distribution or reproduction in other forums is permitted, provided the original author(s) and the copyright owner(s) are credited and that the original publication in this journal is cited, in accordance with accepted academic practice. No use, distribution or reproduction is permitted which does not comply with these terms. 